\title{
Torn Between Valences: Mixed Emotions Predict Poorer Psychological Well-Being and Job Burnout
}

\author{
Vincent Y. S. $\mathrm{Oh}^{1}$ (D)
}

Accepted: 13 December 2021 / Published online: 23 January 2022

(c) The Author(s), under exclusive licence to Springer Nature B.V. 2021

\begin{abstract}
Conflicting perspectives on whether mixed emotions are adaptive states which promote integrative processes or uncomfortable states which are agonizing make divergent predictions on whether mixed emotions in daily life are conducive towards psychological wellbeing. We examined this across three studies. Study $1\left(N=335,135\right.$ males; $\left.M_{\text {age }}=41.31\right)$ examined associations between state mixed emotions and psychological well-being. Study $2\left(N=389 ; 160\right.$ males; $\left.M_{\mathrm{age}}=40.86\right)$ examined associations between workplace-specific mixed emotions and workplace ill-being assessed based on burnout. Both direct measures and indirect measures were examined in Study 1 and 2, allowing some comparison of methodological issues related to their predictive validity. Study 3 ( $N=3444 ; 1587$ males; $M_{\text {age }}=55.34$ ) examined bidirectional relationships between an index of emotional ambivalence and psychological well-being about ten years later, controlling for baselines. Demographic covariates, positive emotions, and negative emotions were controlled for in all studies. Analyses were performed using latent variable structural equation modelling. After adjusting for all covariates, the direct measures of mixed emotions predicted poorer psychological well-being (Study 1) and greater burnout (Study 2). However, indirect measures were found to suffer from relatively greater multicollinearity and poorer predictive validity upon controlling for positive and negative emotions. In Study 3, emotional ambivalence predicted poorer long-term psychological well-being, while psychological well-being also predicted lower emotional ambivalence, supporting bidrectionality. The findings provide preliminary evidence that naturalistically experienced mixed emotions may be conflicting and unpleasant, with potentially negative implications for psychological well-being over and above positive and negative emotions.
\end{abstract}

Keywords Burnout $\cdot$ Mixed affect $\cdot$ Mixed emotions $\cdot$ Emotional ambivalence . Psychological well-being

Vincent Y. S. Oh

vincent.ohys@u.nus.edu

1 Department of Psychology, National University of Singapore, Singapore, Singapore 


\section{Introduction}

When awaiting the outcome of an important job application, we may feel hopeful yet fearful. Receiving a promotion over a colleague may be joyful yet guilt-inducing. Indeed, beyond positive and negative emotions, our emotional world also consists of ambivalent emotional states in which positive and negative emotions are co-activated (Larsen \& McGraw, 2011; Moeller et al., 2018). However, the role of such mixed emotions in contributing to various life outcomes remains poorly understood. Several theorists suggest that mixed emotions are complex states which serve adaptive integrative functions (Rees et al., 2013), yet others instead argue that mixed emotions are problematic and conflicting states requiring resolution (van Harreveld et al., 2009). In the present research, we examine whether naturalistic mixed emotions experienced in the moment would be associated with immediate ratings of psychological well-being (Study 1), whether domain-specific mixed emotions experienced at work would predict workplace burnout (Study 2), as well as bidirectional long-term relationships between an index of general emotional ambivalence and psychological well-being approximately a decade later after adjustments for baseline (Study 3). Secondarily, we also addressed methodological questions concerning the predictive validity of direct versus indirect measures of mixed emotions in Study 1 and 2.

An influential perspective of mixed emotions, which we term the integrative hypothesis, is that mixed emotions are adaptive complex states that facilitate one's ability to integrate information within one's environment, leading to more complex psychological processes such as receptivity and creativity (Fong, 2006; Rees et al., 2013). In turn, mixed emotional states are thought to facilitate positive well-being outcomes. For example, the coactivation model of healthy coping predicts that moderate levels of mixed emotions may be adaptive during adversity by facilitating better integration of both positive and negative information about individuals' circumstances, which is in turn thought to promote resilience (Larsen et al., 2003). From this perspective, experiences of mixed emotions arising from daily life could similarly allow individuals to more effectively make sense of their circumstances and cope better with difficulties, which should ultimately translate to better psychological well-being.

While there is some evidence of this, methodological characteristics of existing studies limit their conclusiveness and generalizability to daily life contexts. For example, some of the evidence linking mixed emotions to positive well-being outcomes are contextualized specifically within adversities. Adler and Hershfield (2012) examined mixed emotions specifically among psychotherapy patients, while Oh and Tong (2021) examined mixed emotions specifically contextualized within the COVID-19 pandemic, which prevents these findings from being generalized to naturalistic mixed emotions arising from daily life. Indeed, theoretical models such as the dynamic model of affect (DMA; Reich et al., 2003) and the co-activation model of healthy coping (Larsen et al., 2003) predict that mixed emotions, either at moderate levels or otherwise, may exert adaptive effects on well-being primarily under conditions of adversity. Other studies that did not focus on adversity have nevertheless examined contextualized mixed emotions (Berrios et al., 2018a, 2018b), such as graduating from college, a primarily positive event that may elicit qualitatively different mixed emotions from those arising naturalistically in daily life. Finally, another study found links between mixed emotions and positive health outcomes (Hershfield et al., 2013) but mixed emotions in this study were operationalized using within-person correlations, which has been criticized as having questionable validity (Larsen et al., 2017). 
The case being made for the adaptive contributions of mixed emotions to well-being is further complicated given that other researchers argue that mixed emotions are uncomfortable states involving a sense of conflict and confusion (Williams \& Aaker, 2002) and that they may hinder goal pursuit unless regulatory processes are enacted to resolve these states (Mejía \& Hooker, 2017). For example, individuals who feel mixed towards a target object tend to evaluate it more negatively (Bee \& Madrigal, 2013), and mixed emotions may be linked to traits which have negative associations with well-being such as neuroticism (Barford \& Smillie, 2016), negative emotions (Barford et al., 2020), and negative life events (Hui et al., 2009). More recently, neuroscientific conceptualizations of mixed emotions have also argued that conflict is the most defining characteristic of mixed emotions (Vaccaro et al., 2020). While none of these studies alone may imply an alternative hypothesis, together they suggest its possibility. Specifically, the conflict hypothesis argues that mixed emotions in daily life may be conflicting and agonizing states that are unlikely to be beneficial for psychological well-being. Indeed, a recent study provided preliminary evidence that nostalgia - which has been widely conceptualized to be a mixed emotional state (Batcho, 2020; Sedikides \& Wildschut, 2018; Vaccaro et al., 2020)—tended to have negative links with well-being when assessed naturalistically (Newman et al., 2020) as opposed to mixed emotions that have often been examined under specific contexts (e.g., Berrios et al., 2018a; Oh \& Tong, 2021). Nevertheless, as nostalgia is a very specific mixed emotional state, it remains unclear whether these findings would generalize to mixed emotions occurring more generally amidst daily life.

In the present research, we provide analyses that seek to address some of the limitations of previous work. Firstly, building upon work that has primarily examined mixed emotions under specific contexts (e.g., Adler \& Hershfield, 2012) or only specific mixed emotional states such as nostalgia (e.g., Newman et al., 2020), our analyses instead focus on generalized, naturalistic, and non-contextualized mixed emotions arising from daily life, which parallels the wealth of evidence that has been surfaced concerning the roles of naturalistic positive and negative emotions in well-being outcomes (Cohn et al., 2009; Fredrickson \& Joiner, 2002; Kuppens et al., 2008). Furthermore, to determine whether mixed states would have unique associations with psychological well-being that are not accounted for by single-valenced emotions (Dejonckheere et al., 2019), we included models that adjusted for positive emotions and negative emotions across all analyses. As comparable work has not been done for mixed emotions, addressing this question would be timely in building upon work on single-valenced emotions or contextualized mixed emotions, thereby advancing theoretical conceptualizations regarding whether naturalistic mixed emotions would show positive or negative relationships with well-being outcomes.

Secondly, we seek to also address measurement issues by testing both direct and indirect measures of mixed emotions where possible. Direct measures of mixed emotions are administered as self-reported Likert scale items, and there is substantial empirical precedence for their use in examining associations between mixed emotions with other variables (e.g., Barford \& Smillie, 2016). Indirect measures are computed from scores for positive and negative emotions-most notably, the minimum index (MIN) has been recommended as a valid measure for indexing the occurrence of mixed emotions (Larsen et al., 2017). Meta-analytic evidence indicates that both direct measures and MIN are valid indices for measuring mixed emotions (Berrios et al., 2015a), and the two measures have also been found to be positively correlated at medium-to-large magnitudes (Berrios et al., 2015b). However, direct measures may potentially suffer from similar drawbacks as other self-reported measures, such as acquiescence biases. Conversely, estimates of mixed emotions are typically smaller when assessed using MIN, and it has been suggested that MIN may underestimate the occurrence of mixed 
emotions (Berrios et al., 2015a). Additionally, as MIN is computed from scores for positive and negative emotions, shared methodological variance may also inflate multicollinearity in models where all emotions are entered simultaneously. The present studies are thus also able to address an auxiliary methodological question concerning statistical properties such as multicollinearity for direct measures and indirect measures, and can compare the predictive validity of these measures for the outcomes of interest in the present research.

We examined the above issues across three datasets. As these datasets were collected prior to the conceptualization of the research question, no pre-registration was performed, but in the interest of transparency, all data and analysis codes are made publicly available. We first examined associations between state mixed emotions and immediate psychological well-being to determine whether mixed emotions would have primarily positive or negative associations with general well-being (Study 1). Subsequently, we examined mixed emotions specifically within the workplace to examine associations between mixed emotions and burnout (Study 2). Finally, we examined bidirectional relationships between an index of general emotional ambivalence and psychological well-being over approximately a decade (Study 3). Importantly, across all studies, we focused on examining naturalistic emotional experiences in daily life rather than contextualized mixed emotions in order to build upon previous single-valenced work that has used similar methodologies to examine emotions and well-being but without examining mixed emotions (e.g., Kuppens et al., 2008), as well as to build upon previous findings which have primarily examined contextualized rather than naturalistic mixed emotions (e.g., Berrios et al., 2018a). To further account for the potential overlap between measures of positive, negative, and mixed emotions, we also performed separate analyses with and without including positive and negative emotions to demonstrate that findings are not due to statistical artefacts resulting from this overlap. Finally, we adjusted for important demographical variables which have been found to be important predictors of well-being, including age (Martin et al., 2001), gender (Pinquart $\&$ Sorensen, 2001), education level (Desjardins, 2008), and income (Kaplan et al., 2008).

\section{STUDY 1}

In Study 1, we examined cross-sectional associations between state mixed emotions and psychological well-being, adjusting for positive emotions, negative emotions, and the key demographical variables outlined above. Psychological well-being was operationalized using Ryff (1989)'s six-factor model of psychological well-being, which argues that eudaimonic well-being can be assessed based on the dimensions of autonomy, environmental mastery, personal growth, positive relations with others, purpose in life, and self-acceptance. Given that there are compelling arguments and studies to support both the integrative and conflict perspectives, we make no a priori predictions in Study 1 and focus on providing empirical tests of these two competing hypotheses.

\section{Method}

\subsection{Participants}

Structural equation modelling (SEM) is typically regarded as a large-sample analysis, and most researchers recommend minimum sample sizes of at least 200 for performing 
SEM, (Kline, 2016), which has also been supported in simulation studies across several conditions (Wolf et al., 2013). Given the relative complexity of the model examined in the present study, we hence aimed to collect a minimum of 300 participants to provide an adequate test of the model. A sample of 335 participants (135 males, 198 females; $M_{\text {age }}=41.31, S D_{\text {age }}=12.51$, age range: $21-78$ years) from the United States (US) were recruited via Amazon Mechanical Turk (MTurk) to complete a short questionnaire. Participants who completed the questionnaire were reimbursed with USD\$1.00. Seven participants were excluded for failing an attention check question, while an additional seven participants were excluded for reporting levels of distraction which were "4" or higher on a seven-point scale. In total, 14 participants were excluded from analyses. The final sample consisted of 321 participants (129 males, 191 females; $M_{\text {age }}=41.64$, $S D_{\text {age }}=12.55$, age range: $22-78$ years). Power analyses indicated that the present sample size would achieve 0.95 power for small-to-medium effect sizes at the conventional alpha of 0.05 . Data and analysis codes for this study are available at https://osf.io/ dukmq/?view_only=a27c4f9b19ec473b83d5adc94615e2e7.

\subsection{Measures}

\subsubsection{State Emotions}

A battery of commonly felt emotion items were administered to assess the degree to which participants felt various positive, negative, and mixed emotions. Similar to approaches utilized in previous research (Kuppens et al., 2008; Nezlek \& Kuppens, 2008; Tong et al., 2021), items were selected to capture a range of common items that represent distinct positive, negative, and mixed emotional states to provide more precise and reliable estimates of each valence. Participants were asked to rate whether they felt each emotion "right now" on a seven-point Likert scale, with the following anchors: 1 (Do not feel the emotion at all), 4 (Feel the emotion moderately), and 7 (Feel the emotion very much). Items within each scale were presented in randomized order.

\subsubsection{Positive Emotions}

19 items were used to measure a broad variety of positive emotions: Proud, Confident, Content, Satisfied, Grateful, Love, Admiration, Determined, Hopeful, Inspired, Courageous, Happy, Amused, Relieved, Excited, Relaxed, Interested, Awe, Impressed. The scale demonstrated strong internal consistency $(\alpha=0.96)$.

\subsubsection{Negative Emotions}

18 items were used to measure a broad variety of negative emotions: Sad, Guilty, Ashamed, Regretful, Afraid, Fearful, Anxious, Embarrassed, Angry, Jealous, Boredom, Disgusted, Disappointed, Dependent, Hostile, Irritated, Contempt, Stressed. The scale demonstrated strong internal consistency $(\alpha=0.95)$. 


\subsubsection{Direct Measure of Mixed Emotions}

18 items were used to measure mixed emotions. The items were adapted based on previous measures of mixed emotions (e.g., Barford \& Smillie, 2016), and additional items were included to assess a broader variety of different specific combinations of mixed emotions: a mix of both happiness and sadness, a mix of both anger and pride, a mix of both amusement and disgust, a mix of both regret and determination, a mix of both jealousy and admiration, a mix of both love and sadness, a mix of both hope and fear, a mix of both sadness and gratitude, a mix of both contentment and sadness, a mix of both determination and sadness, a mix of both relief and disappointment, a mix of both pride and fear, bittersweet, sentimental, nostalgic, a combination of opposing emotions at the same time, a mixture of positive and negative emotions at the same time, contrasting positive and negative emotions at the same time. The scale demonstrated strong internal consistency $(\alpha=0.96)$. The parceled indicators for the scale loaded strongly and significantly into its latent factor $(\lambda \mathrm{s}>0.80)$, and attempting to specify a higher-order factor encompassing all three emotion valences led to non-convergence, suggesting that the scale for mixed emotions reliably captures a unique aspect of affective experiences that is not collapsible with positive and negative affective states.

\subsubsection{Minimum Index (MIN) of Mixed Emotions}

The minimum index, which is computed by taking the smaller of the two values between positive emotions and negative emotions (Larsen et al., 2017), was included as an indirect measure of mixed emotions.

\subsubsection{Psychological Well-Being}

Ryff (1989)'s 42-item scale of psychological well-being was administered. Participants were asked to consider whether each statement was true of them "right now" and to rate the statements on a seven-point Likert scale from 1 (Strongly Disagree) to 7 (Strongly Agree). The scale consists of six seven-item subscales assessing diverse aspects of psychological well-being, including autonomy (e.g. "My decisions are not usually influenced by what everyone else is doing."), environmental mastery (e.g. "I am quite good at managing the many responsibilities of my daily life."), personal growth (e.g. "I have the sense that I have developed a lot as a person over time."), positive relations with others (e.g. "Most people see me as loving and affectionate."), purpose in life (e.g. "I enjoy making plans for the future and working to make them a reality."), and self-acceptance (e.g. "In general, I feel confident and positive about myself."). The six subscales each demonstrated good internal consistency: autonomy ( $\alpha=0.84)$, environmental mastery $(\alpha=0.92)$, personal growth $(\alpha=0.85)$, positive relations with others $(\alpha=0.88)$, purpose in life $(\alpha=0.86)$, selfacceptance $(\alpha=0.92)$. Overall internal consistency for the full scale of psychological wellbeing was strong ( $\alpha=0.96$ ). 


\subsection{Demographics}

Age, gender $(1=$ female, $0=$ male), education level (from 1 representing "no education or some grade school" to 12 representing "PhD or other comparable qualifications") and annual household income (from 0 representing "No income" to 43 representing " $\$ 300,000$ or more") were assessed as demographical covariates.

\subsection{Checks}

One attention check measure was administered to filter out participants who were not responding properly to the survey: "Life is highly meaningful, but for this question select the option "5" to show that you are paying attention.". Participants who failed to select "5" for this question were excluded from analyses. In addition, participants were asked about the extent to which they were distracted while completing the survey on a seven-point Likert scale from 1 (Not at all) to 7 (Very much). Participants who reported distraction levels which were "4" or above were excluded from analyses.

\subsection{Results}

Descriptive statistics are summarized in Table 1, while a correlation matrix is provided in Supplementary Table S1 (observed variables) and Supplementary Table S2 (latent variables). The direct measure of mixed emotions and MIN showed a strong positive correlation $(r=0.72, p<0.001)$, suggesting substantial overlap in the underlying construct being assessed. Unsurprisingly given their conceptual and methodological overlaps, the direct measure of mixed emotions was also correlated with positive emotions $(r=0.19$, $p<0.001)$ and negative emotions $(r=0.67, p<0.001)$, and MIN was also correlated with positive emotions $(r=0.12, p=0.038)$ and negative emotions $(r=0.86, p<0.001)$, supporting the need to control for these emotions to conclude an additional explanatory role of mixed emotions (Dejonkcheere et al., 2019). However, preliminary analyses indicated that MIN suffered from substantially more severe multicollinearity $(\mathrm{VIF}=4.78)$ compared to the direct measure $(\mathrm{VIF}=2.18)$ in models where positive and negative emotions were included. While these values for VIF do not exceed conventional thresholds for concluding severe multicollinearity (e.g., VIF < 5; James et al., 2013), losses in statistical power may still occur when multicollinearity is heightened and sample size is not especially large (Mason \& Perreault, 1991), thus necessitating caution in interpreting models where MIN is included while controlling for positive and negative emotions. Initial bivariate analyses suggested that mixed emotions were negatively correlated with psychological well-being both when assessed using direct measures $(r=-0.33, p<0.001)$ as well as when using MIN $(r=-0.36, p<0.001)$.

We then performed latent variable structural equation modelling using the lavaan package on $R$, which allowed us to account for measurement errors and hence provide more accurate tests (Kline, 2016). To account for the possibility that multicollinearity between mixed emotions and positive or negative emotions could lead to artificial findings, we tested models in which mixed emotions-indexed using either direct measures or MINwere tested as predictors of psychological well-being both with and without controlling for positive and negative emotions. As the number of items for each scale were very large, we followed the recommendations of Landis et al. (2000) and utilized randomized parceling 


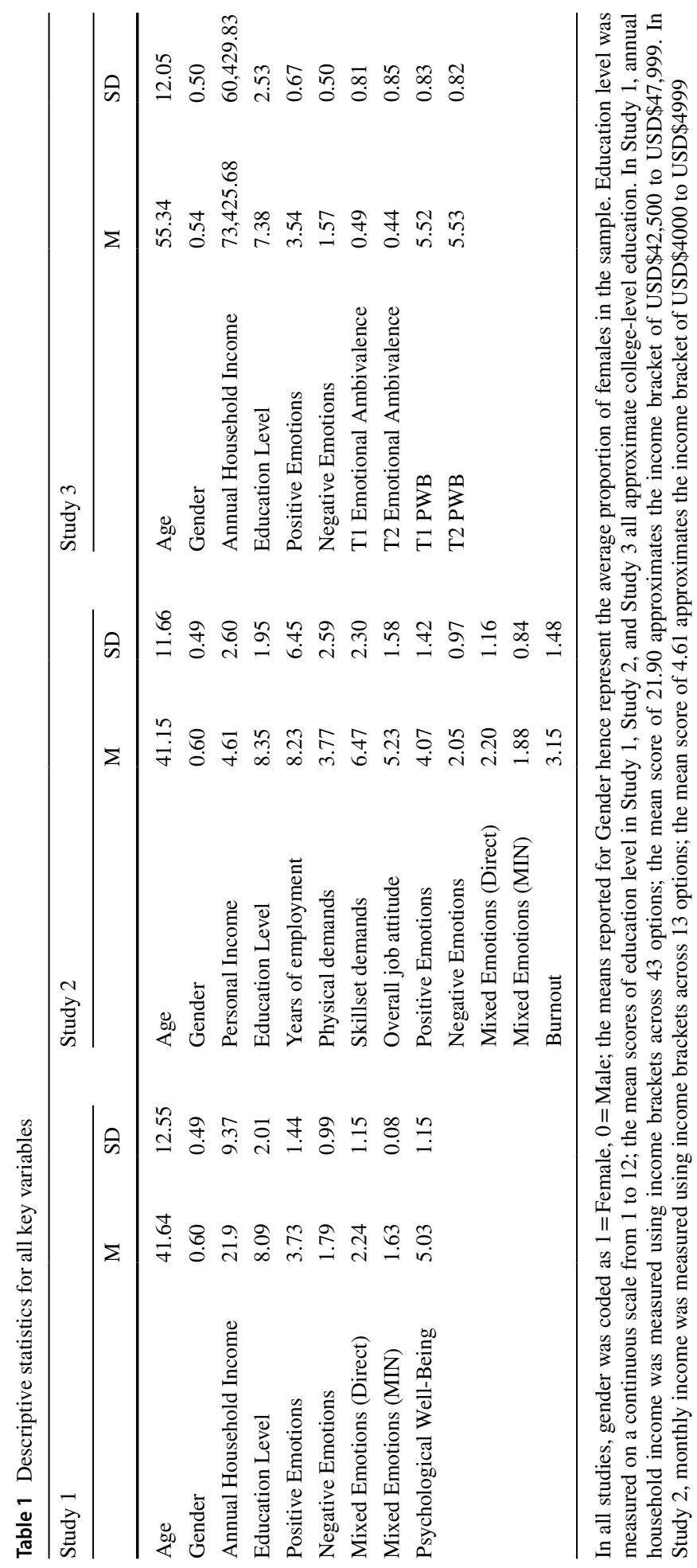


Table 2 Latent variable path coefficients predicting psychological well-Being from direct measures and the minimum index in Study 1 (without controlling for positive and negative emotions)

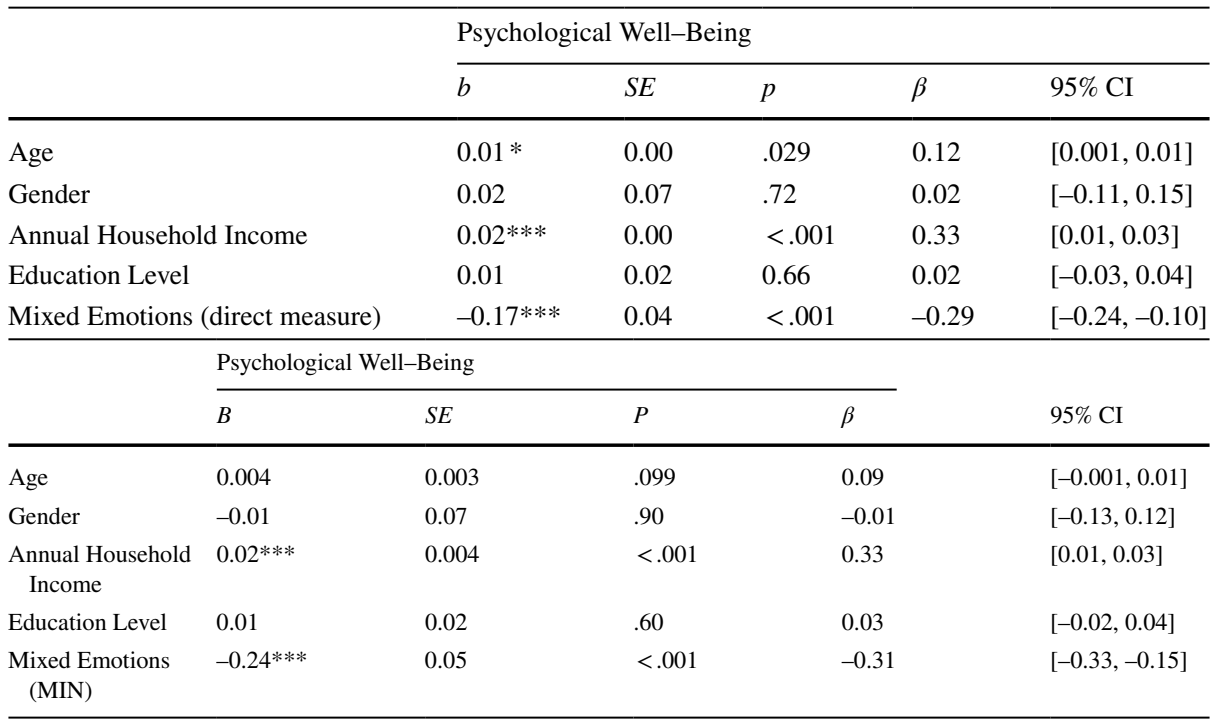

${ }^{*} p<.05, * * p<.01, * * * p<.001$. Model fit was acceptable for the measurement model using direct measures $\left[\chi^{2}(223)=591.46, p<.001, \mathrm{CFI}=0.94, \mathrm{RMSEA}=0.072, \mathrm{SRMR}=0.058\right]$ as well as the measurement model using MIN $\left[\chi^{2}(146)=409.72, p<.001, \mathrm{CFI}=0.95, \mathrm{RMSEA}=0.075, \mathrm{SRMR}=0.054\right]$

to reduce the number of indicators per latent factor. Specifically, items measuring positive, negative, and mixed emotions were respectively randomized into five parcels each which were specified as indicators for their respective latent factors.

For each subscale of psychological well-being, we first randomly assigned the corresponding seven items into three parcels each. Given previous evidence that the six dimensions of the psychological well-being scale have strong overlaps and may not capture distinct aspects of psychological well-being (Burns \& Machin, 2009; Springer et al., 2006), a higher order factor encompassing the six dimensions was specified to provide an overall index of psychological well-being, which also enables greater interpretative parsimony and clarity. Confirmatory factor analyses provided evidence that model fit was acceptable across all models (see Tables 2 and 3), and all six dimensions of psychological well-being loaded strongly and significantly into the higher-order factor, thus supporting the reliability of the higher-order factor in indexing overall psychological well-being: autonomy $(\lambda=0.51)$, environmental mastery $(\lambda=0.93)$, personal growth $(\lambda=0.79)$, positive relations $(\lambda=0.84)$, purpose in life $(\lambda=0.86)$, self-acceptance $(\lambda=0.95)$, all $p$-values $<0.001$. In the interest of transparency, analyses in which the six factors are analyzed separately are reported under Supplementary Analyses A.

Next, we specified and tested the structural models. All predictors were allowed to covary to account for their theoretical and methodological overlaps. As shown in Table 2, in models without positive and negative emotions, both the direct measure and MIN significantly predicted poorer psychological well-being, providing preliminary support for the conflict hypothesis. As shown in Table 3, after including positive emotions and negative emotions as covariates, the direct measure remained predictive of poorer psychological well-being, which provides preliminary initial evidence that mixed emotions may explain variance in psychological well-being uniquely from positive and negative emotions. However, the association between MIN and psychological well-being fell to non-significance 
Table 3 Latent variable path coefficients predicting psychological well-being from direct measures and the minimum index in Study 1 (controlling for positive and negative emotions)

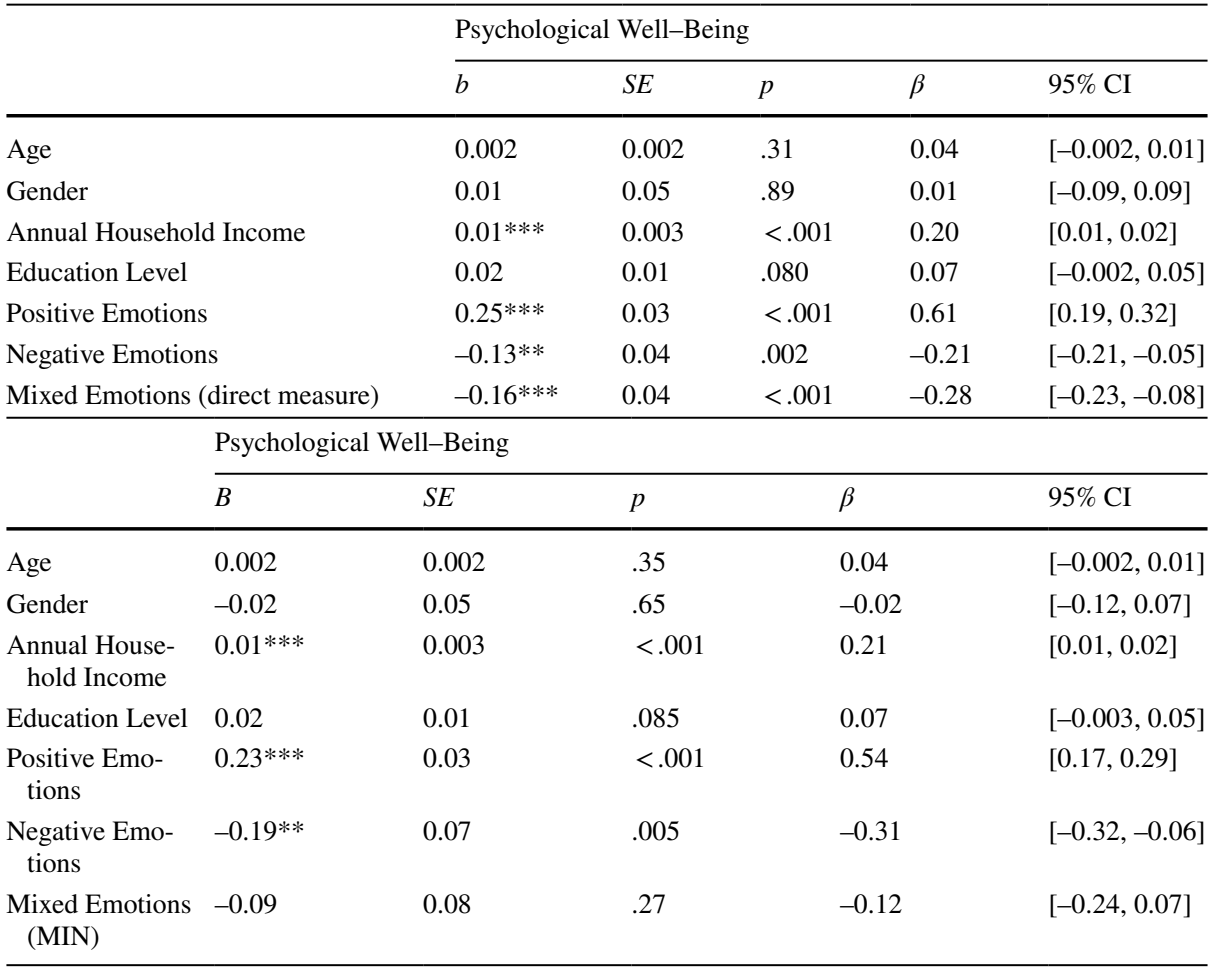

$* p<.05, * * p<.01, * * * p<.001$. Model fit was acceptable for the measurement model using direct measures $\left[\chi^{2}(483)=1251.24, p<.001, \mathrm{CFI}=0.93, \mathrm{RMSEA}=0.070, \mathrm{SRMR}=0.067\right]$ as well as the measurement model using MIN $\left[\chi^{2}(366)=985.09, p<.001, \mathrm{CFI}=0.93, \mathrm{RMSEA}=0.073, \mathrm{SRMR}=0.066\right]$

after controlling for positive and negative emotions, though it is unclear whether this could be due to losses in statistical power or statistical artifacts owing to inflated multicollinearity for MIN.

\section{Study 2}

Study 1 provided preliminary evidence supporting the conflict hypothesis, such that state mixed emotions assessed using direct measures predicted poorer psychological well-being after adjusting for positive emotions, negative emotions, and demographical covariates. However, findings using indirect measures were less consistent—specifically, while MIN similarly predicted poorer psychological well-being, this association became non-significant upon adjusting for positive and negative emotions, though inflated multicollinearity makes this finding difficult to interpret. Preliminarily, we speculate that MIN may have poorer predictive validity in models where positive and negative emotions are controlled for, possibly due to inflated multicollinearity and reduced statistical power (Mason \& Perreault, 1991) given that MIN is computed from scores for positive and negative 
emotions, which would substantially increase shared methodological variance between these measures.

In Study 2, we extended our investigation of both our theoretical and methodological questions by focusing on emotional experiences within a specific domain - the workplace. In addition to providing conceptual replication of our findings in Study 1, extending these findings to the workplace would also provide substantial practical contributions. As the Ryff (1989) measure of psychological well-being does not have a workplace equivalent, workplace ill-being was indexed based on burnout, which is well-established as a critical marker of maladjustment in the workplace (Maslach et al., 2001). Indeed, burnout is linked to numerous detrimental outcomes, including suicidal risk (Dyrbye et al., 2008; Taris, 2006), and hundreds of billions are estimated to be lost annually due to unhappy workers (Gallup, 2017), making this an issue of practical importance as well.

A key methodological refinement made in Study 2 is noteworthy. Although cross-sectional studies cannot provide evidence of causality, applying stringent statistical controls guided by strong theoretical considerations can strengthen conclusions about a predictor's predictive validity even after key extraneous variables have been identified and adjusted for (Becker et al., 2016). We thus adjusted for objective job characteristics that can be linked to burnout, including participants' wages (Jiang \& Probst, 2017) and the number of years of employment in their present job (Brewer \& Shapard, 2004). As job demands are well-established antecedents of burnout (Demerouti et al., 2001), we also adjusted for participants' subjective evaluations of whether their occupations are demanding of physical labor or specialized skillsets. Finally, to determine whether recent mixed emotions experienced in the workplace predict current levels of job burnout independently of participants' overall evaluation of their jobs, we adjusted for the overall affective attitude that participants have towards their jobs.

Study 2 hence provides a stringent test of whether mixed emotions experienced at work would predict job burnout beyond single-valenced emotions (positive and negative), demographics (age, gender, education level), objective job characteristics (monthly wages and years of employment), subjective job characteristics (perceived physical demand and perceived skillset demand), and overall affective attitude towards one's job. In line with Study 1, we expected that the direct measure of mixed emotions would predict greater burnout after controlling for all covariates. We sought to again test and compare MIN against the direct measure, but we made no specific predictions for MIN given that findings from Study 1 were mixed.

\section{Method}

\subsection{Participants}

As per Study 1, we aimed to collect a minimum of 300 participants. A sample of 389 participants (160 males, 229 females; $M_{\text {age }}=40.86, S D_{\text {age }}=11.58$, age range: $22-76$ years) from US were recruited via Amazon MTurk to complete a short questionnaire about their work experiences. Participants were required to be full-time employees to be eligible for the study. Participants who completed the questionnaire were reimbursed with USD\$1.00. Two participants were flagged as fraudulent by Qualtrics' fraud detection software and were excluded from analyses. Thirteen participants failed an open-ended attention check question and were also excluded from analyses. Finally, an additional nine participants were excluded for reporting that they were distracted during the survey. In total, 24 participants were excluded from analyses. The final sample consisted of 365 participants (145 
males, 220 females; $M_{\text {age }}=41.15, S D_{\text {age }}=11.66$, age range: $22-76$ years). Power analyses indicated that the present sample size would achieve 0.95 power for small-to-medium effect sizes at the conventional alpha of 0.05 . Data and analysis codes for this study are available at https://osf.io/dukmq/?view_only=a27c4f9b19ec473b83d5adc94615e2e7.

\subsection{Measures}

\subsubsection{Emotions at Work}

A battery of commonly felt emotion items were administered to assess the degree to which participants felt various positive, negative, and mixed emotions during the last five days that they were at work. Participants were asked to rate whether they felt each emotion " $d u r$ ing the last five days that they were at work" on a seven-point Likert scale, with the following anchors: 1 (Did not feel the emotion at all at work), 4 (Felt the emotion moderately at work), and 7 (Felt the emotion very much at work). Items within each scale were presented in randomized order.

\subsubsection{Positive Emotions}

The same 19 items from Study 1 were used to measure positive emotions experienced at work. The scale demonstrated strong internal consistency $(\alpha=0.96)$.

\subsubsection{Negative Emotions}

The same 18 items from Study 1 were used to measure negative emotions experienced at work. The scale demonstrated strong internal consistency $(\alpha=0.94)$.

\subsubsection{Direct Measure of Mixed Emotions}

23 items were used to measure mixed emotions. The same items as Study 1 were used to assess mixed emotions experienced at work, with the exception that five additional items were included to assess additional variants of mixed emotions: A mix of both gratitude and guilt at the same time, A mix of both regret and pride at the same time, A mix of both fear and courage at the same time, A mix of both sadness and amusement at the same time, A mix of both anger and determination at the same time. The scale demonstrated strong internal consistency $(\alpha=0.97)$. Similar to Study 1 , the parceled indicators for the scale loaded strongly and significantly into its latent factor $(\lambda \mathrm{s}>0.80)$, and specifying a higher-order factor across all three emotional valences again led to non-convergence, suggesting that the scale reliably captures mixed emotions that are not collapsible with positive and negative emotions.

\subsubsection{Minimum Index of Mixed Emotions}

As per Study 1, we computed MIN by taking the smaller of the two values between positive emotions and negative emotions (Larsen et al., 2017) to provide an indirect measure of mixed emotions ${ }^{1}$.

1 A strict definition of mixed emotions is that positive and negative emotions are co-occurring simultaneously. This definition is incorporated into the direct measure of mixed emotions, allowing face validity in 


\subsection{Copenhagen Burnout Inventory}

The 13-item Copenhagen Burnout Inventory, a well-validated measure with strong psychometric properties (Kristensen et al., 2005), was used to assess burnout (e.g., "When thinking about your job at the present moment, do you think: 'I can't take it anymore'?"). Participants were instructed to answer the questions based on "thinking about their job at the present moment". The scale demonstrated strong internal consistency ( $\alpha=0.95$ ).

\subsection{Occupational Characteristics}

A series of questions were administered to determine participants' objective and subjective perceptions of their occupation's characteristics.

\subsubsection{Years of Employment}

An open-ended question was used to assess the number of years they have been employed in their current occupation: "How many years have you been employed in this job?".

\subsubsection{Monthly Income}

Participants reported their monthly personal income in US dollars on a 13-point Likert scale from 1 (Less than $\$ 1000$ ) to 13 (More than \$12,000), with increments of $\$ 1000$ between each bracket.

\subsubsection{Physical Demands}

One item was used to assess whether participants perceived their job as being physically demanding: "How physically demanding is your job in comparison to other jobs?" The item was answered on a 10-point Likert scale from 1 (Little to no physical labor) to 10 (Extreme physical labor).

\subsubsection{Skillset Demands}

One item was used to assess whether participants perceived their job as requiring specialized skillsets: "How specialized do you feel is your current occupation?" The item was answered on a 10-point Likert scale from 1 (Anyone can do the job) to 10 (Only few have the skills for the job).

Footnote 1 (continued)

assessing mixed emotions with the direct measures. However, as emotions are measured over the 'last five days' in Study 2, simultaneity cannot be determined when using indirect indices, so mixed emotions measured by MIN in this study may provide a less stringent measure. We nevertheless included this measure here for the purposes of examining the methodological questions highlighted previously. 


\subsubsection{Overall Job Attitudes}

Two items were used to assess whether participants had an overall positive view of their job on a 7-point Likert scale from 1 (Not at all) to 7 (Very much): "Taking into account everything about your job, to what extent would you say you feel positively about your job?" and "Taking into account everything about your job, to what extent would you say you feel negatively about your job? (reverse-coded)". The scale demonstrated strong internal consistency $(\alpha=0.89)$.

\subsection{Demographics}

Age, gender $(1=$ female, $0=$ male), education level (from 1 representing "no education or some grade school" to 12 representing "PhD or other comparable qualifications") were assessed as demographical covariates.

\subsection{Checks}

An open-ended attention check was administered whereby participants were instructed to write about their free time in exactly three sentences. Participants who did not comply with these instructions were excluded. Participants who reported being distracted during the survey $(1=$ Yes, $0=N o)$ were also excluded from analyses.

\subsection{Results}

Descriptive statistics ${ }^{2}$ are summarized in Table 1, while the full correlation matrix is provided in Supplementary Table S1 (observed variables) and Supplementary Table S2 (latent variables). Much like in Study 1, the direct measure of mixed emotions and MIN showed a strong positive correlation $(r=0.77, p<0.001)$, indicative of substantial overlap. Similarly, the direct measure of mixed emotions was also correlated with positive emotions $(r=0.16$, $p<0.001)$ and negative emotions $(r=0.64, p<0.001)$. However, MIN was not correlated with positive emotions $(r=0.01, p=0.85)$, but was strongly correlated with negative emotions $(r=0.83, p<0.001)$. Furthermore, much like in Study 1 , preliminary analyses again indicated that MIN suffered from substantially more severe multicollinearity (VIF=4.61) compared to the direct measure ( $\mathrm{VIF}=2.26$ ) in models where positive and negative emotions were included. MIN may thus be more strongly conflated with negative affect and may be vulnerable to methodological issues concerning multicollinearity, thus necessitating caution in interpreting models where MIN is included while controlling for positive and negative emotions. Nevertheless, initial bivariate analyses suggested that mixed

\footnotetext{
${ }^{2}$ Mean scores for the direct measures of mixed emotions were higher than negative affect as well as MIN in both Study 1 and 2. Speculatively, subjective experiences of mixed emotions-which are tapped into by direct measures but not the indirect approach of MIN - may incorporate intensities from both positive and negative affect, which may lead to stronger subjective experiences of mixed emotions than negative emotions. Indeed, this is consistent with evidence which has found that mixed emotions were more common than purely negative emotions (Barford et al., 2020), and is also consistent with previous evidence that MIN may estimate lower boundaries of mixed emotional experiences (Berrios et al., 2015a).
} 
Table 4 Latent variable path coefficients predicting burnout in Study 2 from direct measures and the minimum index (without controlling for positive and negative emotions)

\begin{tabular}{|c|c|c|c|c|c|c|}
\hline & & Burnout & & & & \\
\hline & & $b$ & $S E$ & $p$ & $\beta$ & $95 \% \mathrm{CI}$ \\
\hline Age & & -0.01 & 0.01 & .23 & -0.05 & {$[-0.02,0.01]$} \\
\hline Gender & & 0.19 & 0.13 & .16 & 0.05 & {$[-0.07,0.44]$} \\
\hline Education Level & & 0.02 & 0.04 & .58 & 0.02 & {$[-0.05,0.09]$} \\
\hline Income & & 0.03 & 0.03 & .23 & 0.05 & {$[-0.02,0.09]$} \\
\hline Years of employm & nent & 0.004 & 0.01 & .73 & 0.02 & {$[-0.02,0.03]$} \\
\hline Physical demands & & $0.06^{*}$ & 0.03 & .017 & 0.10 & {$[0.01,0.12]$} \\
\hline Skillset demands & & $0.10 * *$ & 0.04 & .003 & 0.14 & {$[0.04,0.17]$} \\
\hline Overall job attituc & & $-0.83 * * *$ & 0.06 & $<.001$ & -0.73 & $\begin{array}{c}{[-0.95,-} \\
0.72]\end{array}$ \\
\hline Mixed Emotions & (direct measure) & $0.38 * * *$ & 0.06 & $<.001$ & 0.27 & {$[0.27,0.50]$} \\
\hline Study 2 & Burnout & & & & & \\
\hline & $b$ & $S E$ & $p$ & & $\beta$ & $95 \% \mathrm{CI}$ \\
\hline Age & -0.01 & 0.01 & .31 & & -0.04 & {$[-0.02,0.01]$} \\
\hline Gender & $0.26^{*}$ & 0.13 & .047 & & 0.08 & {$[0.003,0.51]$} \\
\hline Education Level & 0.03 & 0.04 & .44 & & 0.03 & {$[-0.04,0.10]$} \\
\hline Income & 0.03 & 0.03 & .21 & & 0.05 & {$[-0.02,0.09]$} \\
\hline $\begin{array}{l}\text { Years of } \\
\text { employment }\end{array}$ & 0.00 & 0.01 & .78 & & 0.01 & {$[-0.02,0.03]$} \\
\hline $\begin{array}{l}\text { Physical } \\
\text { demands }\end{array}$ & $0.07 * *$ & 0.03 & .005 & & 0.11 & {$[0.02,0.12]$} \\
\hline Skillset demands & $0.11 * *$ & 0.04 & .002 & & 0.15 & {$[0.04,0.18]$} \\
\hline $\begin{array}{l}\text { Overall job } \\
\text { attitude }\end{array}$ & $-0.82 * * *$ & 0.06 & $<.001$ & & -0.71 & $\begin{array}{c}{[-0.94,-} \\
0.70]\end{array}$ \\
\hline $\begin{array}{l}\text { Mixed Emotions } \\
\text { (MIN) }\end{array}$ & $0.49 * * *$ & 0.08 & $<.001$ & & 0.25 & {$[0.33,0.65]$} \\
\hline
\end{tabular}

$* p<.05, * * p<.01, * * * p<.001$. Model fit was largely acceptable for the measurement model using direct measures $\left[\chi^{2}(41)=196.34, p<.001, \mathrm{CFI}=0.97, \mathrm{RMSEA}=0.10, \mathrm{SRMR}=0.053\right]$ as well as the measurement model using $\mathrm{MIN}\left[\chi^{2}(12)=97.22, p<.001, \mathrm{CFI}=0.97, \mathrm{RMSEA}=0.14, \mathrm{SRMR}=0.040\right]$, but RMSEA was somewhat inflated in these models where positive and negative emotions were not included

emotions were positively correlated with burnout both when assessed using direct measures $(r=0.39, p<0.001)$ as well as when using MIN $(r=0.44, p<0.001)$.

We then performed latent variable structural equation modelling using the lavaan package on $R$. As per Study 1, we tested models using both the direct measure of mixed emotions and MIN, and we tested models with and without controlling for positive and negative emotions. We first specified and tested the measurement model using confirmatory factor analyses. Using the same procedure as Study 1, we performed randomized parceling to reduce the number of indicators for each latent factor. Specifically, items measuring positive, negative, and mixed emotions were respectively randomized into five parcels respectively, while burnout was randomized into four parcels. Overall job attitude was also specified as a latent factor comprising two indicators. Confirmatory factor analyses provided evidence that model fit was generally acceptable across all models (see Tables 4 and 5), although RMSEA tended to be somewhat inflated in models where positive and negative 
Table 5 Latent variable path coefficients predicting burnout in Study 2 from direct measures and the minimum index (controlling for positive and negative emotions)

\begin{tabular}{|c|c|c|c|c|c|c|c|c|}
\hline & & & Burnout & & & & & \\
\hline & & & $b$ & $S E$ & $p$ & & $\beta$ & $95 \% \mathrm{CI}$ \\
\hline Age & & & -0.01 & 0.01 & .29 & & -0.04 & {$[-0.02,0.01]$} \\
\hline Gender & & & 0.18 & 0.12 & .15 & & 0.05 & {$[-0.06,0.42]$} \\
\hline Education Level & & & 0.02 & 0.03 & .47 & & 0.03 & {$[-0.04,0.09]$} \\
\hline Income & & & 0.02 & 0.03 & .40 & & 0.03 & {$[-0.03,0.07]$} \\
\hline Years of employı & nent & & 0.003 & 0.01 & .78 & & 0.01 & {$[-0.02,0.02]$} \\
\hline Physical demand & & & $0.07 *$ & 0.03 & .010 & & 0.10 & {$[0.02,0.12]$} \\
\hline Skillset demands & & & $0.11 * *$ & 0.03 & .001 & & 0.15 & {$[0.04,0.17]$} \\
\hline Overall job attitu & & & $-0.54 * * *$ & 0.11 & $<.001$ & & -0.47 & $\begin{array}{c}{[-0.74,-} \\
0.33]\end{array}$ \\
\hline Positive Emotion & & & $-0.19 *$ & 0.08 & .022 & & -0.16 & $\begin{array}{c}{[-0.35,-} \\
0.03]\end{array}$ \\
\hline Negative Emotio & & & $0.43 * *$ & 0.14 & .003 & & 0.25 & {$[0.15,0.72]$} \\
\hline Mixed Emotions & (direct measure) & & $0.24 * *$ & 0.09 & .008 & & 0.16 & {$[0.06,0.41]$} \\
\hline Study 2 & Burnout & & & & & & & \\
\hline & $b$ & $S E$ & & $p$ & & $\beta$ & & $95 \% \mathrm{CI}$ \\
\hline Age & -0.01 & 0.01 & & .29 & & -0.04 & & {$[-0.02,0.01]$} \\
\hline Gender & 0.21 & 0.13 & & .10 & & 0.06 & & {$[-0.04,0.46]$} \\
\hline Education Level & 0.03 & 0.03 & & .34 & & 0.04 & & {$[-0.03,0.10]$} \\
\hline Income & 0.02 & 0.03 & & .45 & & 0.03 & & {$[-0.03,0.07]$} \\
\hline $\begin{array}{l}\text { Years of employ- } \\
\text { ment }\end{array}$ & 0.00 & 0.01 & & .91 & & 0.01 & & {$[-0.02,0.02]$} \\
\hline Physical demands & $0.08 * *$ & 0.03 & & .003 & & 0.12 & & {$[0.03,0.13]$} \\
\hline Skillset demands & $0.11 * *$ & 0.03 & & .001 & & 0.15 & & {$[0.04,0.17]$} \\
\hline $\begin{array}{l}\text { Overall job } \\
\text { attitude }\end{array}$ & $-0.45^{* * *}$ & 0.13 & & .001 & & -0.40 & & {$[-0.70,-0.19]$} \\
\hline Positive Emotions & -0.15 & 0.08 & & .060 & & -0.13 & & {$[-0.31,0.01]$} \\
\hline $\begin{array}{l}\text { Negative Emo- } \\
\text { tions }\end{array}$ & $0.78 * *$ & 0.28 & & .006 & & 0.44 & & {$[0.23,1.33]$} \\
\hline $\begin{array}{l}\text { Mixed Emotions } \\
\text { (MIN) }\end{array}$ & -0.08 & 0.24 & & .75 & & -0.04 & & {$[-0.54,0.39]$} \\
\hline
\end{tabular}

$* p<.05, * * p<.01, * * * p<.001$. Model fit was acceptable for the measurement model using direct measures $\left[\chi^{2}(179)=561.47, p<.001, \mathrm{CFI}=0.96, \mathrm{RMSEA}=0.077, \mathrm{SRMR}=0.057\right]$ as well as the measurement model using MIN $\left[\chi^{2}(110)=384.72, p<.001, \mathrm{CFI}=0.96, \mathrm{RMSEA}=0.083, \mathrm{SRMR}=0.054\right]$

emotions were excluded, suggesting that the exclusion of positive and negative emotions from the models may increase error.

Next, we specified and tested the structural model. All predictors were allowed to covary to account for their theoretical and methodological overlaps. As shown in Table 4, in models where positive and negative emotions were not included, both the direct measure of mixed emotions as well as MIN significantly predicted higher job burnout. Replicating the findings of Study 1, as shown in Table 5, the direct measure ${ }^{3}$ of mixed emotions remained

\footnotetext{
3 3. Could direct measures of mixed emotions be tapping into acquiescence instead? We explored this in Study 1 and 2 based on the recommendations of researchers who proposed using structural equation modelling to account for acquiescence (Kam \& Zhou, 2015; Kuru \& Pasek, 2016; Savalei \& Falk, 2014). Even after accounting for either (1) an acquiescence factor specifically for mixed emotions or (2) an acquiescence
} 
predictive of higher job burnout even after accounting for positive and negative emotions, which provides further evidence preliminarily supporting the conflict hypothesis. However, also replicating Study 1, MIN was no longer predictive of job burnout upon the inclusion of positive and negative emotions, though the relatively higher multicollinearity of this index complicates interpretations.

\section{Study 3}

Study 2 found that direct measures of mixed emotions at work were associated with higher job burnout even after controlling for positive and negative emotions as well as other covariates, providing conceptual replication of Study 1's finding by looking at domain-specific mixed emotions and ill-being. Conversely, analyses using MIN encountered similar difficulties as was found in Study 1, such that multicollinearity was relatively higher, which may account for why associations between MIN and burnout fell to non-significance upon accounting for positive and negative emotions.

Study 3 builds upon these findings in several ways. Firstly, a key limitation of Study 1 and 2 is that their cross-sectional design prevents clear inferences of causal directionality. Indeed, existing studies on mixed emotions and well-being outcomes have generally focused only on relatively short-term associations, and their long-term predictive value hence remains unclear. Related to this, mixed emotions are often activated by negative situations (Hui et al., 2009) and negative traits (Barford \& Smillie, 2016), which suggests the possibility that cross-sectional associations may represent the tendency of individuals with poorer well-being to experience more mixed emotions. Long-term analyses of bidirectionality may provide clearer evidence of whether mixed emotions predict well-being, whether well-being predicts mixed emotions, or if both pathways may be supported. In Study 3, we analyzed data from a large-scale public dataset, the Midlife Development in the United States (MIDUS) study, which provided information on participants' emotional experiences and psychological well-being across two time points spanning about a decade. The dataset thus enables cross-lagged panel modelling to test for long-term, bidirectional associations. While cross-lagged approaches do not provide definitive evidence of causality, they nevertheless provide good evidence of directional or bidirectional relationships even after controlling for baselines.

Secondly, as direct measures of mixed emotions were unavailable in MIDUS, we used an index to calculate general emotional ambivalence (Breckler, 1994; Thompson et al., 1995). Unlike Study 1 and 2, the adverse effects of multicollinearity on statistical power should theoretically be less severe in Study 3 (Mason \& Perreault, 1991), where the sample size is close to ten times larger than Study 1 and 2. Although comparisons with direct measures are unavailable in this study, Study 3 nevertheless allows us to examine whether

Footnote 3 (continued)

factor specified across all emotion measures, the direct measure of mixed emotions remained predictive of poorer psychological well-being in Study 1 ( $p s<.001)$. In Study 2, the direct measure of mixed emotions similarly remained predictive of burnout after specifying an acquiescence factor for mixed emotions $(p=.021)$. Specifying an acquiescence factor across all emotion measures led to non-convergence in Study 2 , but inspecting the regression coefficients nevertheless suggests that the direct measure of mixed emotions continued to predict increased burnout $(p=.026)$. There is hence no strong evidence that acquiescence is likely to account for the reported findings. 
indirect measures may have better predictive validity for well-being outcomes under conditions of much larger sample sizes where multicollinearity can be addressed. While the ambivalence index cannot directly tap into mixed emotions given that it references the past 30 days of emotional experiences and does not directly assess simultaneous experiences of positive and negative emotions, it provides an indirect indication of how ambivalent one's emotional states may tend to be in daily life using a high-powered sample of adult participants. Indeed, similar procedures have been commonly used to assess mixed emotions or emotional ambivalence in other studies (Hong \& Lee, 2010; Schneider \& Mattes, 2021; Spencer-Rodgers et al., 2010). Study 3 hence provides longitudinal, large-sample evidence that complements the cross-sectional evidence from Study 1 and 2. In line with the results of Study 1 and 2, we hypothesized that emotional ambivalence would predict poorer longterm psychological well-being after controlling for baseline psychological well-being and demographical covariates.

\subsection{Method}

\subsubsection{Participants}

The MIDUS is a multi-phase longitudinal study which drew from a nationally representative random-digit-dial sample of participants from the US. Specifically, participants completed the MIDUS2 Main Survey conducted between 2004 and 2006, which contained data about participants' general experience of positive and negative emotions as well as their baseline psychological well-being. Participants completed a phone interview, followed by a questionnaire that was sent via mail. Data from MIDUS2 served as the first time point (T1) for the present analyses. Subsequently, data from the MIDUS3 Main Survey, conducted between 2013 and 2014, served as the second time point (T2) and provided information on the outcome variables of interest. Similar to MIDUS2, participants completed a phone interview and a mailed questionnaire. In total, 3444 participants provided complete data at T1 (1587 males, 1857 females; $M_{\text {age }}=55.34, S D_{\text {age }}=12.05$, age range: $30-84$ years). Substantial attrition was present, such that complete data across T1 and T2 was available for 2155 participants (981 males, 1174 females; $M_{\text {age }}=54.77, S D_{\text {age }}=11.04$, age range: 30-84 years). Power analyses indicated that the present sample size would permit even the detection of small effect sizes at the conventional alpha of 0.05 and a power of above 0.99 . Data for this study is available from http://www.midus.wisc.edu/, while analysis codes are available from https://osf.io/dukmq/?view_only=a27c4f9b19ec473b83d5adc94615e2e7.

\subsection{Measures}

\subsubsection{Positive Emotions}

13 items were administered to assess the frequency with which participants felt various positive emotions in the past 30 days on a five-point Likert scale from 1 (None of the time) to 5 (All the time): "cheerful", "good spirits", "extremely happy", "calm and peaceful", "satisfied", "full of life", "close to others", "like you belong", "enthusiastic", "attentive", "proud", "active", and "confident". Internal consistency for the scale was good $(\alpha=0.92)$. 


\subsubsection{Negative Emotions}

14 items were administered to assess the frequency with which participants felt various positive emotions in the past 30 days on a five-point Likert scale from 1 (None of the time) to 5 (All the time): "so sad no one could cheer you up", "nervous", "restless", "everything was an effort", "hopeless", "worthless", "lonely", "afraid", "jittery", "irritable", "ashamed", "upset", "angry", and "frustrated". Internal consistency for the scale was good $(\alpha=0.94)$.

\subsubsection{Emotional Ambivalence}

We calculated emotional ambivalence at both T1 and T2 using an established emotional ambivalence index, using a procedure recommended by Breckler (1994). Firstly, the weaker affect (MIN) was calculated by taking the smaller value of the two between positive affect and negative affect. Secondly, the stronger affect (MAX) was calculated by taking the larger value of the two between positive affect and negative affect. Finally, emotional ambivalence was computed using the following formula: $\frac{M I N+M A X}{2}-|M I N-M A X|$. This index has several key properties that enable it to assess emotional ambivalence (Breckler, 1994; Thompson et al., 1995). Firstly, an increase in MIN should be tracked by the index as increasing ambivalence, as this indicates that the weaker affect is conflicting more with the stronger affect. Secondly, decreases in MAX should be tracked by the index as increasing ambivalence, as this indicates that the stronger affect is becoming less dominant over the weaker affect, suggesting ambivalence. Thirdly, holding MIN and MAX equal, increasing values of MIN/MAX should indicate more intense affective states in conflict and hence increasing ambivalence. Breckler (1994) found that this formula was most appropriate for these purposes and recommended its usage. Indeed, this index as well as variations ${ }^{4}$ of this index have been very widely used in both recent (Buder et al., 2021; Schneider \& Mattes, 2021) as well as previous (Hong \& Lee, 2010; Spencer-Rodgers et al., 2010) research to index ambivalent or complex emotional states and are well-validated.

\subsubsection{Psychological Well-Being}

The same 42-item scale of psychological well-being (Ryff, 1989) outlined in Study 1 was administered for Study 3 as well. The scale was administered at both T1 (analyzed as a baseline covariate) as well as T2 (analyzed as the key outcome variable). Internal consistency of the six subscales at T1 were good: autonomy $(\alpha=0.71)$, environmental mastery ( $\alpha=0.78)$, personal growth $(\alpha=0.75)$, positive relations with others $(\alpha=0.78)$, purpose in life $(\alpha=0.70)$, self-acceptance $(\alpha=0.84)$. Overall internal consistency for the full scale of psychological well-being at T1 was strong as well $(\alpha=0.93)$. At T2, internal consistency

\footnotetext{
4 There are slight variations in the exact formula that different researchers have used to calculate mixed emotions or emotional ambivalence, such as $3 \times M I N-M A X$ (Hong \& Lee, 2010) and $[2 \times M I N]+1$ $(M I N+M A X+2)($ Spencer-Rodgers et al., 2010). These different indices are functionally equivalent and are virtually identical ( $r \mathrm{~s}>.99)$. As was done in Studies 1 and 2, MIN can also be used directly as an index of mixed emotions, though the index may be less valid for Study 3 given that emotions are measured with reference to the past 30 days, which enables an estimate of general ambivalence rather than simultaneous positive and negative emotions. Nevertheless, when analyses were repeated using these other indices instead, all key findings remained consistent $(p s<.01)$.
} 
of the six subscales were good as well: autonomy $(\alpha=0.69)$, environmental mastery ( $\alpha=0.80)$, personal growth $(\alpha=0.75)$, positive relations with others $(\alpha=0.77)$, purpose in life $(\alpha=0.72)$, self-acceptance $(\alpha=0.84)$. Overall internal consistency for the full scale of psychological well-being at T2 was also strong $(\alpha=0.93)$.

\subsubsection{Demographics}

Age, gender $(1=$ female, $0=$ male), education level (from 1 representing "no education or some grade school" to 12 representing "PhD or other comparable qualifications") and annual household income were assessed as demographical covariates. Due to its large numerical value, annual household income was standardized prior to analyses to provide more interpretable regression coefficients.

\subsection{Results}

Descriptive statistics are summarized in Table 1, while the correlation matrix is provided in Supplementary Table S1 (observed variables) and Supplementary Table S2 (latent variables). Given that emotional ambivalence was computed using scores of positive and negative emotions, T1 emotional ambivalence was correlated with positive emotions $(r=-0.72, p<0.001)$ and negative emotions $(r=0.82, p<0.001)$. Multicollinearity statistics (VIF $=4.79$ for $\mathrm{T} 1$ emotional ambivalence) were similar to those when using MIN in Studies 1 and 2, though we expect that the especially large sample size of Study 3 should alleviate losses of statistical power. Initial bivariate analyses suggest negative correlations between T1 emotional ambivalence and T2 psychological well-being $(r=-0.47$, $p<0.001)$. Analyses were then performed using the lavaan package on $R$, and a latent variable cross-lagged panel model was examined to test long-term bidirectional relationships between emotional ambivalence and psychological well-being about a decade later after controlling for baselines. This analytic strategy is well-validated and consistent with many other recent analyses of the MIDUS dataset (Dewitte et al., 2020; Hartanto et al., 2019; Tong et al., 2021; Wiese et al., 2019) as well as of other longitudinal datasets (Orth et al., 2021)..$^{5}$ Additionally, we addressed missing data using full information maximum likelihood (FIML) procedures, which are widely considered the gold standard for handling missing data (Enders \& Bandalos, 2001). ${ }^{6}$

Following the same procedure as Study 1 and 2, we specified and tested the measurement model both with and without including positive and negative emotions using confirmatory factor analyses. Emotional ambivalence at T1 and T2 were specified as a single-item latent variable calculated based on the above index. For the remaining scales, we performed randomized parceling, ${ }^{7}$ as per Study 1 and 2. Specifically, items for positive and

\footnotetext{
5 Additional analyses were performed to check for endogeneity, which refers to the problem in which predictors in a model may covary with the model's error term (Lynch \& Brown, 2011), and to determine whether criteria for measurement invariance in psychological wellbeing was met (Chen et al., 2005; Kim et al., 2017). No evidence was found for endogeneity, and analyses indicated that the scale for psychological well-being met criteria for scalar invariance across measurement occasions and across levels of emotional ambivalence. These analyses are reported in more detail under Supplementary Analyses B.

6 All key results remained consistent $(p s<.005)$ with or without the application of FIML procedures to address missing data, attesting to the robustness of the findings.

7 As the number of items in each study is very large, specifying all indicators without parceling will inevitably lead to poor model fit in latent variable approaches which favor parsimony, and parceling has been
} 
negative emotions were respectively randomized into five parcels each. Like in Study 1, the six latent factors of psychological well-being were each specified as comprising three indicators parceled from the original seven items within each subscale, and overall psychological well-being was specified as a higher-order latent factor comprising the six lower-order latent factors. This was done at T1 as well as T2, and covariances were specified between each indicator at $\mathrm{T} 1$ and the corresponding indicators at $\mathrm{T} 2$ to account for their shared measurement error. As in Study 1, factor loadings were again strong and significant, supporting the reliability of the higher-order factor: autonomy $\left(\lambda_{T 1}=0.64 ; \lambda_{T 2}=0.63\right)$, environmental mastery $\left(\lambda_{T 1}=0.97 ; \lambda_{T 2}=0.97\right)$, personal growth $\left(\lambda_{T 1}=0.83 ; \lambda_{T 2}=0.83\right)$, positive relations $\left(\lambda_{T 1}=0.83 ; \lambda_{T 2}=0.83\right)$, purpose in life $\left(\lambda_{T 1}=0.92 ; \lambda_{T 2}=0.92\right)$, self-acceptance $\left(\lambda_{T 1}=0.97 ; \lambda_{T 2}=0.97\right)$, all $p$-values $<0.001$. Model fit based on the above specifications was acceptable (see Table 6). Analyses of the six dimensions separately are also reported in Supplementary Analyses A.

Having established model fit for the measurement models, we proceeded to specify and test the structural models. We examined whether T1 emotional ambivalence would predict T2 psychological well-being, controlling for the autoregressive pathway between T1 psychological well-being and T2 psychological well-being to account for baseline psychological well-being. Furthermore, we also examined whether T1 psychological wellbeing would predict T2 emotional ambivalence, controlling for the autoregressive pathway between $\mathrm{T} 1$ emotional ambivalence and T2 emotional ambivalence. All demographic covariates were adjusted for in all pathways. At each time point, covariances were also specified between emotional ambivalence and psychological well-being to account for cross-sectional relationships before examining cross-lagged associations. All predictors were allowed to covary to account for their overlaps at baseline.

As shown in Table 6, results indicated that T1 emotional ambivalence predicted poorer T2 psychological well-being about ten years later even after controlling for baseline psychological well-being and other demographical covariates. Furthermore, even after further controlling for positive and negative emotions, this association remained significant, suggesting that emotional ambivalence has unique explanatory power for future psychological well-being that is not accounted for by positive and negative emotions. Furthermore, the results also suggest that $\mathrm{T} 1$ psychological well-being significantly predicted lower emotional ambivalence at $\mathrm{T} 2$ after controlling for T1 emotional ambivalence. The results hence support bidirectional long-term relationships between emotional ambivalence and psychological well-being. The cross-lagged panel model is depicted in Fig. 1.

\section{General Discussion}

Across three studies, we found initial suggestive evidence supporting the conflict hypothesis over the integrative hypothesis, such that mixed emotions and emotional ambivalence experienced naturalistically in daily life were associated with poorer psychological well-being and increased burnout, in contrast to mixed emotions that are situated under more specific contexts such as adversity (Larsen et al., 2003). These findings largely held across both direct

Footnote 7 (continued)

recommended as a valid approach to addressing this issue (Little et al., 2013). Importantly, however, even when parceling was not performed and all indicators were specified directly, all key findings remained consistent $(p \mathrm{~s}<.01)$. Thus, the main conclusions remained consistent with or without parceling. 


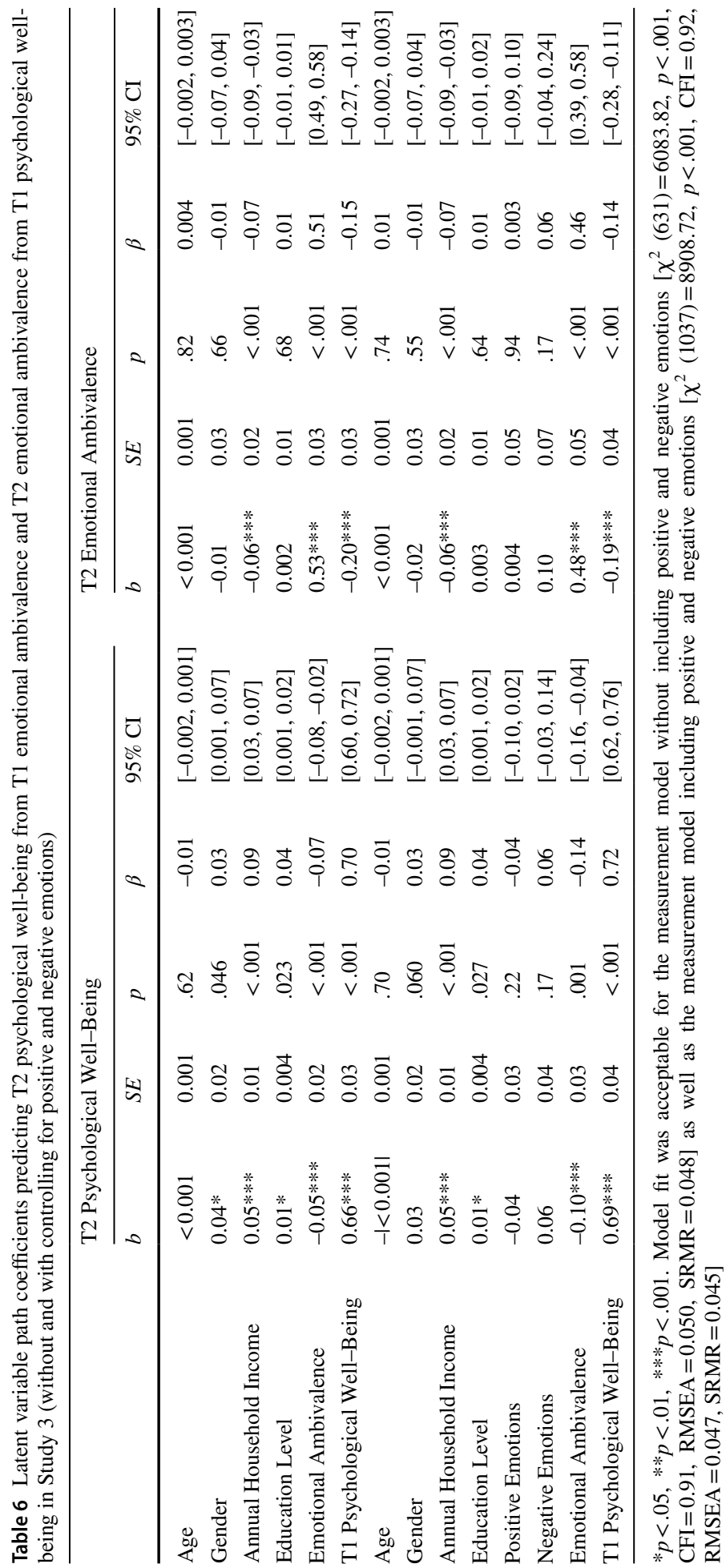




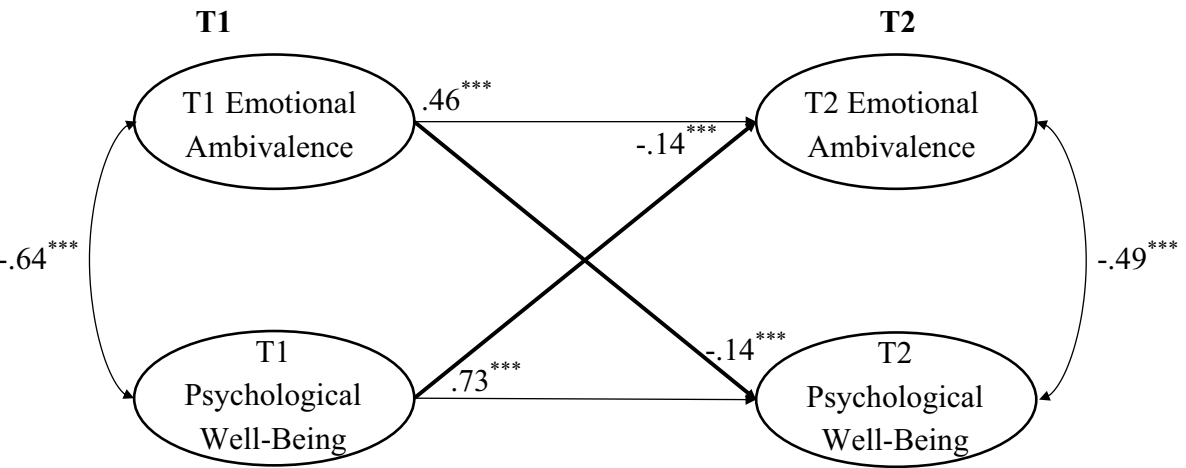

Fig. 1 Longitudinal cross-lagged panel model of bidirectional associations between emotional ambivalence and psychological well-being in Study 3. Bolded lines represent significant non-autoregressive paths. All coefficients provided are standardized latent variable coefficients. $* * * p<.001$. Positive emotions, negative emotions, age, gender, education level, and household income were controlled for in all pathways

and indirect measures, though indirect measures suffered from greater multicollinearity and showed less consistent findings upon controlling for positive and negative emotions. Nevertheless, the overall findings provide conceptual replication of Newman et al. (2020), who found that naturalistic experiences of nostalgia, a mixed emotion, were associated with negative psychosocial outcomes. Additionally, in Study 3, we found evidence to support bidirectional long-term associations between emotional ambivalence and psychological well-being, which is consistent with findings showing that mixed emotions may be activated in negative situations and by negative traits (e.g., Barford \& Smillie, 2016; Miyamoto et al., 2010).

Importantly, our findings do not imply that the integrative hypothesis is an invalid model of mixed emotions-rather, we speculate that the specific contexts under which mixed emotions arise may be crucial to determining which hypothesis is supported. For example, several theoretical models ${ }^{8}$ predict that mixed emotions may be more conducive to wellbeing outcomes under conditions of adversity (e.g., Larsen et al., 2003). Moreover, much of the evidence supporting the integrative hypothesis has examined contextualized mixed emotions such as those resulting from important events (Berrios et al., 2018a) or adversities (Adler \& Hershfield, 2012) rather than mixed emotions occurring naturalistically from daily life (see Kuppens et al., 2008 for an example of such work but focusing on singlevalenced emotions.) The present research hence extends upon previous work on contextualized mixed emotions (Berrios et al., 2018a), non-contextualized but highly-specific mixed emotions (Newman et al., 2020), as well as non-contextualized single-valenced emotions where mixed emotions were not tested (e.g., Kuppens et al., 2008), and the findings provide initial evidence that mixed emotions in daily life contexts are conflicting, uncomfortable, and may explain variance in well-being in negative directions. Indeed, some previous

\footnotetext{
${ }^{8}$ It is also possible that only moderate levels of mixed emotions are adaptive (e.g., Miyamoto \& Ryff, 2011), which would be supported by a reverse-U-shaped curvilinear trend. Other researchers have proposed that a moderate positivity ratio (indicating a balance between positive and negative emotions, which may also provide a limited measure of emotional ambivalence) could be more adaptive for well-being outcomes (Shrira et al., 2011). We explored these possibilities but found no evidence that moderate levels of mixed emotions or a moderate positivity ratio was linked to better well-being in the naturalistic daily life contexts examined here. These analyses are reported under Supplementary Analyses C.
} 
evidence suggests that the tendency to experience fluctuating and variable emotions could be a marker of psychological dysfunction (Carolan \& Power, 2011; Silvers et al., 2016), and non-contextualized mixed emotions that arise under naturalistic contexts may similarly be markers of psychological distress, in line with the conflict hypothesis. These findings thus also highlight the importance of context in emotions research, given that associations between emotions and specific outcomes could differ substantially depending on the specific contexts under which these emotions are elicited (Newman et al., 2020).

A secondary issue we examined concerned the predictive validity of using direct versus indirect approaches to measuring mixed emotions (Berrios et al., 2015a). In Studies 1 and 2, direct measures and MIN were highly correlated and were related to the key outcomes with very similar regression coefficients. However, relative to direct measures, MIN was more strongly correlated with negative emotions and exhibited more severe multicollinearity when entered alongside positive and negative emotions. Indeed, whereas the direct measures remained predictive of well-being outcomes after controlling for positive and negative emotions, MIN demonstrated poorer predictive validity upon controlling for positive and negative emotions. Speculatively, in analyses that aim to determine whether mixed emotions have independent associations from positive and negative emotions (Dejonckheere et al., 2019), MIN may suffer from lower statistical power due to increased multicollinearity, and a much larger sample size may be required to alleviate losses in power (Mason \& Perreault, 1991). Indeed, in Study 3 where the available sample size was tenfold that of Study 1 and 2, an indirect index similar to MIN maintained its predictive validity despite similar multicollinearity statistics as was found in Study 1 and 2. We emphasize however that these findings are heavily preliminary and do not imply that direct measures are necessarily superior to MIN, as direct measures may suffer from different limitations, possibly in relation to reporting biases not examined in the present studies. More extensive tests comparing MIN to direct measures across a larger variety of outcomes are necessary to provide more conclusive evidence concerning statistical issues with these measures.

With the exception of analyses using MIN in Study 1 and 2 which were found to have limited interpretability due to multicollinearity, the main findings largely held even in models where positive emotions and negative emotions were adjusted for (Dejonckheere et al., 2019). Thus, there is preliminary evidence suggesting that mixed emotions may have unique contributions to psychological well-being and burnout that are not accounted for by their single-valenced counterparts. Theoretically, this further supports the idea that mixed emotions are distinctive emotional experiences, with downstream associations that may not be fully explained by positive or negative emotions (e.g., Rees et al., 2013). Moreover, across all studies, the magnitudes of associations between mixed emotions and well-being outcomes were comparable to or larger than those of income, which is well-established as a practically important antecedent of well-being (Diener et al., 2010), while age, gender, education level, and workplace characteristics generally tended to have smaller or non-significant effects. While directional conclusions are preliminary and tentative, the findings minimally suggest that mixed emotions may play a substantial explanatory role for wellbeing and ill-being even in comparison to other important life variables. Given that losses in psychological well-being or the experience of burnout can have severe personal (Dyrbye et al., 2008) and organizational (Girard et al., 2019) costs, future applied research can further examine directional links between mixed emotions and well-being outcomes, as well as how such experiences may be effectively regulated.

We note several limitations and future directions. Firstly, the present studies do not permit definitive causal conclusions, given the absence of experimental manipulations. However, the primary goal of the present research was not to establish causality but to 
examine naturalistic associations between mixed emotions and well-being, which is not possible within an artificial experimental setting. The present studies permit ecologically valid conclusions pertaining to the explanatory power of mixed emotions for psychological well-being and burnout, and Study 3 also provides suggestive evidence that ambivalent emotional states could be linked to poorer long-term psychological well-being even after stringent adjustments for baseline. A key methodological refinement that may be pursued in future work is to replicate the present findings using experience sampling methodologies. While experience sampling methods are not without limitations (Scollon et al., 2003) and are also more costly to execute, these methods provide strong approaches to examining directionality in naturalistic contexts and may be valuable in future research.

Secondly, direct measures of mixed emotions were unavailable in Study 3, and comparisons between direct and indirect measures were hence not possible. While the index of emotional ambivalence cannot provide a direct assessment of mixed emotions, it is nevertheless a valid and well-established approach to estimating whether participants' general emotional experiences tend to be ambivalent (Breckler, 1994; Buder et al., 2021; Hong \& Lee, 2010; Schneider \& Mattes, 2021; Spencer-Rodgers et al., 2010). Coupled with the large-scale, longitudinal dataset used in Study 3, this approach thus provides evidence complementing Study 1 and 2 about how ambivalent emotional states could be directionally linked to well-being. Additionally, the large sample size available in Study 3 also allowed an indirect test of our speculation that larger sample sizes are required to overcome losses in statistical power when using indirect indices of mixed emotions. Nevertheless, future work should also examine direct measures of mixed emotions within a longitudinal framework, and should further compare direct and indirect measures of mixed emotions across a wider variety of outcomes. Additionally, building upon the measures of well-being and ill-being used in the present studies, examining other indirect indicators such as physiological or behavioral markers of stress (Abbott et al., 1984; Feldman et al., 1999) would also provide important methodological and conceptual replication of the present findings.

Thirdly, some researchers argue that mixed emotions may be more adaptive within contexts of adversity (Larsen et al., 2003; Reich et al., 2003), and indeed we speculate that our findings in support of the conflict hypothesis may be more applicable to naturalistic contexts. As noted, some indirect evidence from previous work is consistent with this view, given that naturalistic experiences of nostalgia, a mixed emotion, has similarly been associated with poorer psychosocial outcomes (Newman et al., 2020), while mixed emotions contextualized within adversities have instead been linked to more positive well-being outcomes (Adler \& Hershfield, 2012; Oh \& Tong, 2021). More direct evidence of this would require research designs in which adversity is explicitly modelled as a moderator-to the extent that mixed emotions become more positively associated with well-being outcomes as adversity increases, more conclusive evidence can be obtained to support the speculation that mixed emotions are more adaptive in adversity contexts but less so in naturalistic, non-adversity contexts. This will likely be an important direction for future research.

Finally, the present research provided evidence that mixed emotions were linked to poorer psychological well-being and increased burnout within naturalistic contexts, but the mechanisms and boundary conditions of these relationships remain unknown. Speculatively, due to opposing cues of positivity and negativity, mixed emotions are often experienced as uncomfortable and conflicting in many contexts (Mikulincer et al., 2010), and may disrupt individuals' sense of coherence in daily life (Costin \& Vignoles, 2019). In turn, the disrupted sense of coherence resulting from mixed emotions may mediate the relationship between mixed emotions and poorer psychological well-being (Pallant \& Lae, 2002), though this remains to be empirically tested. Some researchers have also argued 
that the extent to which mixed emotions result in negative evaluations may be moderated by individual differences related to the tolerance of ambiguity or the ability to construe stimuli in complex ways (Hong \& Lee, 2010; Williams \& Aaker, 2002). Related to this, East Asian cultures may also be more tolerant of mixed emotions (Miyamoto et al., 2017). Future work should thus examine whether the implications of mixed emotions for psychological well-being may depend on such individual or cultural differences.

In sum, the present research provided evidence that naturalistically experienced mixed emotions in daily life were associated with poorer psychological being and increased burnout, and the findings largely held after adjusting for positive emotions, negative emotions, and other demographical covariates. We also provided a preliminary investigation comparing statistical issues involving the predictive validity of using direct versus indirect measures of mixed emotions. Whereas previous work has suggested that mixed emotions may promote integrative potential and positive outcomes in some contexts, our findings provided more support for the conflict hypothesis in the context of naturalistically experienced mixed emotions in daily life and suggest that mixed emotions may not always lead to positive outcomes. Thus, our findings advance theoretical conceptualizations of mixed emotions as a distinct affective state which can have important practical implications for well-being.

Supplementary Information The online version contains supplementary material available at https://doi. org/10.1007/s10902-021-00493-z.

Funding No funds, grants, or other support was received.

\section{Declarations}

Conflicts of interest The authors have no conflicts of interest to declare that are relevant to the content of this article.

Ethical approval The research has received ethics approval from the National University of Singapore Institutional Review Board (IRB) and informed consent was obtained from all participants.

\section{References}

Abbott, B. B., Schoen, L. S., \& Badia, P. (1984). Predictable and unpredictable shock: behavioral measures of aversion and physiological measures of stress. Psychological Bulletin, 96, 45-71. https://doi.org/10. 1037/0033-2909.96.1.45

Adler, J. M., \& Hershfield, H. E. (2012). Mixed emotional experience is associated with and precedes improvements in psychological well-being. PLOS ONE, 7, e35633. https://doi.org/10.1371/journal. pone.0035633

Barford, K. A., Koval, P., Kuppens, P., \& Smillie, L. D. (2020). When good feelings turn mixed: affective dynamics and big five trait predictors of mixed emotions in daily life. European Journal of Personality, 34, 393-411. https://doi.org/10.1002/per.2264

Barford, K. A., \& Smillie, L. D. (2016). Openness and other big five traits in relation to dispositional mixed emotions. Personality and Individual Differences, 102, 118-122. https://doi.org/10.1016/j.paid.2016. 07.002

Batcho, K. I. (2020). When nostalgia tilts to sad: anticipatory and personal nostalgia. Frontiers in Psychology, 11, 1186. https://doi.org/10.3389/fpsyg.2020.01186

Becker, T. E., Atinc, G., Breaugh, J. A., Carlson, K. D., Edwards, J. R., \& Spector, P. E. (2016). Statistical control in correlational studies: 10 essential recommendations for organizational researchers: statistical control in correlational studies. Journal of Organizational Behavior, 37, 157-167. https://doi.org/10. 1002/job.2053 
Bee, C. C., \& Madrigal, R. (2013). Consumer uncertainty: the influence of anticipatory emotions on ambivalence, attitudes, and intentions: consumer uncertainty and anticipatory emotions. Journal of Consumer Behaviour, 12, 370-381. https://doi.org/10.1002/cb.1435

Berrios, R., Totterdell, P., \& Kellett, S. (2015a). Eliciting mixed emotions: a meta-analysis comparing models, types, and measures. Frontiers in Psychology. https://doi.org/10.3389/fpsyg.2015.00428

Berrios, R., Totterdell, P., \& Kellett, S. (2015b). Investigating goal conflict as a source of mixed emotions. Cognition and Emotion, 29, 755-763. https://doi.org/10.1080/02699931.2014.939948

Berrios, R., Totterdell, P., \& Kellett, S. (2018a). When feeling mixed can be meaningful: the relation between mixed emotions and eudaimonic well-being. Journal of Happiness Studies, 19, 841-861. https://doi.org/10.1007/s10902-017-9849-y

Berrios, R., Totterdell, P., \& Kellett, S. (2018b). Silver linings in the face of temptations: how mixed emotions promote self-control efforts in response to goal conflict. Motivation and Emotion, 42, 909-919. https://doi.org/10.1007/s11031-018-9707-1

Bollen, K. A. (1989). A new incremental fit index for general structural equation models. Sociological Methods \&amp; Research, 17, 303-316. https://doi.org/10.1177/0049124189017003004

Breckler, S. J. (1994). A comparison of numerical indexes for measuring attitude ambivalence. Educational and Psychological Measurement, 54, 350-365. https://doi.org/10.1177/0013164494054002009

Brewer, E. W., \& Shapard, L. (2004). Employee burnout: a meta-analysis of the relationship between age or years of experience. Human Resource Development Review, 3, 102-123. https://doi.org/10.1177/15344 84304263335

Buder, J., Rabl, L., Feiks, M., Badermann, M., \& Zurstiege, G. (2021). Does negatively toned language use on social media lead to attitude polarization? Computers in Human Behavior, 116, 106663. https://doi.org/10.1016/j.chb.2020.106663

Burns, R. A., \& Machin, M. A. (2009). Investigating the structural validity of Ryff's psychological wellbeing scales across two samples. Social Indicators Research, 93, 359-375. https://doi.org/10.1007/ s11205-008-9329-1

Carolan, L. A., \& Power, M. J. (2011). What basic emotions are experienced in bipolar disorder? Clinical Psychology and Psychotherapy, 18, 366-378. https://doi.org/10.1002/cpp.777

Chen, F. F. (2007). Sensitivity of goodness of fit indexes to lack of measurement invariance. Structural Equation Modeling: A Multidisciplinary Journal, 14, 464-504. https://doi.org/10.1080/10705 510701301834

Chen, F. F., Sousa, K. H., \& West, S. G. (2005). Teacher's corner: testing measurement invariance of second-order factor models. Structural Equation Modeling: A Multidisciplinary Journal, 12, 471492. https://doi.org/10.1207/s15328007sem1203_7

Cohn, M. A., Fredrickson, B. L., Brown, S. L., Mikels, J. A., \& Conway, A. M. (2009). Happiness unpacked: positive emotions increase life satisfaction by building resilience. Emotion, 9, 361-368. https://doi.org/10.1037/a0015952

Costin, V., \& Vignoles, V. L. (2019). Meaning is about mattering: evaluating coherence, purpose, and existential mattering as precursors of meaning in life judgments. Journal of Personality and Social Psychology. https://doi.org/10.1037/pspp0000225

Dejonckheere, E., Mestdagh, M., Houben, M., Rutten, I., Sels, L., Kuppens, P., \& Tuerlinckx, F. (2019). Complex affect dynamics add limited information to the prediction of psychological well-being. Nature Human Behaviour, 3, 478-491. https://doi.org/10.1038/s41562-019-0555-0

Demerouti, E., Bakker, A. B., Nachreiner, F., \& Schaufeli, W. B. (2001). The job demands-resources model of burnout. Journal of Applied Psychology, 86, 499-512. https://doi.org/10.1037/0021-9010. 86.3.499

Desjardins, R. (2008). Researching the links between education and well-being: European journal of education. European Journal of Education, 43, 23-35. https://doi.org/10.1111/j.1465-3435.2007.00333.x

Dewitte, L., Lewis, N. A., Payne, B. R., Turiano, N. A., \& Hill, P. L. (2020). Cross-lagged relationships between sense of purpose in life, memory performance, and subjective memory beliefs in adulthood over a 9-year interval. Aging \&amp; Mental Health. https://doi.org/10.1080/13607863.2020.1822284

Diener, E., Ng, W., Harter, J., \& Arora, R. (2010). Wealth and happiness across the world: material prosperity predicts life evaluation, whereas psychosocial prosperity predicts positive feeling. Journal of Personality and Social Psychology, 99, 52-61. https://doi.org/10.1037/a0018066

Dyrbye, L. N., Thomas, M. R., Massie, F. S., Power, D. V., Eacker, A., Harper, W., Durning, S., Moutier, C., Szydlo, D. W., Novotny, P. J., Sloan, J. A., \& Shanafelt, T. D. (2008). Burnout and suicidal ideation among u S medical students. Annals of Internal Medicine, 149, 334. https://doi.org/10.7326/ 0003-4819-149-5-200809020-00008 
Enders, C., \& Bandalos, D. (2001). The relative performance of full information maximum likelihood estimation for missing data in structural equation models. Structural Equation Modeling: A Multidisciplinary Journal, 8, 430-457. https://doi.org/10.1207/S15328007SEM0803_5

Feldman, P. J., Cohen, S., Lepore, S. J., Matthews, K. A., Kamarck, T. W., \& Marsland, A. L. (1999). Negative emotions and acute physiological responses to stress. Annals of Behavioral Medicine, 21, 216-222. https://doi.org/10.1007/BF02884836

Fong, C. T. (2006). The effects of emotional ambivalence on creativity. Academy of Management Journal, 49, 1016-1030. https://doi.org/10.5465/amj.2006.22798182

Fredrickson, B. L., \& Joiner, T. (2002). Positive emotions trigger upward spirals toward emotional wellbeing. Psychological Science, 13, 172-175. https://doi.org/10.1111/1467-9280.00431

Gallup. (2017). State of the American Workplace. Retrieved from: https://www.gallup.com/workplace/ 238085/state-american-workplace-report-2017.aspx

Girard, D. E., Nardone, D. A., Hickam, D. H., \& Goldfarb, T. (2019). Estimating the attributable cost of physician burnout in the united states. Annals of Internal Medicine, 171, 600. https://doi.org/10. 7326/L19-0521

Hartanto, A., Yong, J., \& Toh, W. (2019). Bidirectional associations between obesity and cognitive function in midlife adults: a longitudinal study. Nutrients, 11(10), 2343. https://doi.org/10.3390/nu11102343

Hershfield, H. E., Scheibe, S., Sims, T. L., \& Carstensen, L. L. (2013). When feeling bad can be good: mixed emotions benefit physical health across adulthood. Social Psychological and Personality Science, 4, 54-61. https://doi.org/10.1177/1948550612444616

Hong, J., \& Lee, A. Y. (2010). Feeling mixed but not torn: The moderating role of construal level in mixed emotions appeals. Journal of Consumer Research, 37, 456-472. https://doi.org/10.1086/653492

James, G., Witten, D., Hastie, T., \& Tibshirani, R. (2013). An introduction to statistical learning Vol. 103. Springer New York. https://doi.org/10.1007/978-1-4614-7138-7

Jiang, L., \& Probst, T. M. (2017). The rich get richer and the poor get poorer: country- and state-level income inequality moderates the job insecurity-burnout relationship. Journal of Applied Psychology, 102(4), 672-681. https://doi.org/10.1037/ap10000179

Kam, C. C. S., \& Zhou, M. (2015). Does acquiescence affect individual items consistently? Educational and Psychological Measurement, 75(5), 764-784. https://doi.org/10.1177/0013164414560817

Kaplan, G. A., Shema, S. J., \& Leite, C. M. A. (2008). Socioeconomic determinants of psychological wellbeing: the role of income, income change, and income sources during the course of 29 years. Annals of Epidemiology, 18, 531-537. https://doi.org/10.1016/j.annepidem.2008.03.006

Kim, E. S., Cao, C., Wang, Y., \& Nguyen, D. T. (2017). Measurement invariance testing with many groups: a comparison of five approaches. Structural Equation Modeling: A Multidisciplinary Journal, 24, 524-544. https://doi.org/10.1080/10705511.2017.1304822

Kline, R. B. (2016). Principles and practice of structural equation modelling 4th eds. New York: Guilford Press.

Kristensen, T. S., Borritz, M., Villadsen, E., \& Christensen, K. B. (2005). The copenhagen burnout inventory: a new tool for the assessment of burnout. Work \&amp; Stress, 19, 192-207. https://doi.org/10. 1080/02678370500297720

Kuppens, P., Realo, A., \& Diener, E. (2008). The role of positive and negative emotions in life satisfaction judgment across nations. Journal of Personality and Social Psychology, 95, 66-75. https://doi.org/10. 1037/0022-3514.95.1.66

Kuru, O., \& Pasek, J. (2016). Improving social media measurement in surveys: avoiding acquiescence bias in Facebook research. Computers in Human Behavior, 57, 82-92. https://doi.org/10.1016/j.chb.2015. 12.008

Landis, R. S., Beal, D. J., \& Tesluk, P. E. (2000). A comparison of approaches to forming composite measures in structural equation models. Organizational Research Methods, 3, 186-207. https://doi.org/10. $1177 / 109442810032003$

Larsen, J. T., Hemenover, S. H., Norris, C. J., \& Cacioppo, J. T. (2003). Turning adversity to advantage: On the virtues of the coactivation of positive and negative emotions. In L. G. Aspinwall \& U. M. Staudinger (Eds.), A psychology of human strengths: Fundamental questions and future directions for a positive psychology. 211-225. https://doi.org/10.1037/10566-015

Larsen, J. T., Hershfield, H., \& HalStastnyHester, E. B. J. N. (2017). On the relationship between positive and negative affect: their correlation and their co-occurrence. Emotion, 17, 323-336. https://doi.org/ $10.1037 / \mathrm{emo} 0000231$

Larsen, J. T., \& McGraw, A. P. (2011). Further evidence for mixed emotions. Journal of Personality and Social Psychology, 100, 1095-1110. https://doi.org/10.1037/a0021846 
Ledgerwood, A., \& Shrout, P. E. (2011). The trade-off between accuracy and precision in latent variable models of mediation processes. Journal of Personality and Social Psychology, 101, 1174-1188. https://doi.org/10.1037/a0024776

Little, T. D., Rhemtulla, M., Gibson, K., \& Schoemann, A. M. (2013). Why the items versus parcels controversy needn't be one. Psychological Methods, 18, 285-300. https://doi.org/10.1037/a0033266

Lynch, S. M., \& Brown, J. S. (2011). Stratification and inequality over the life course. In Handbook of Aging and the Social Sciences. p. 105-117. Elsevier. https://doi.org/10.1016/B978-0-12-380880-6.00008-3

Martin, M., Grunendahl, M., \& Martin, P. (2001). Age differences in stress, social resources, and well-being in middle and older age. The Journals of Gerontology Series b: Psychological Sciences and Social Sciences, 56, 214-222. https://doi.org/10.1093/geronb/56.4.P214

Maslach, C., Schaufeli, W. B., \& Leiter, M. P. (2001). Job burnout. Annual Review of Psychology, 52, 397422. https://doi.org/10.1146/annurev.psych.52.1.397

Mason, C. H., \& Perreault, W. D. (1991). Collinearity, power, and interpretation of multiple regression analysis. Journal of Marketing Research, 28, 268. https://doi.org/10.2307/3172863

Mejía, S. T., \& Hooker, K. (2017). Mixed emotions within the context of goal pursuit. Current Opinion in Behavioral Sciences, 15, 46-50. https://doi.org/10.1016/j.cobeha.2017.05.015

Mikulincer, M., Shaver, P. R., Bar-On, N., \& Ein-Dor, T. (2010). The pushes and pulls of close relationships: attachment insecurities and relational ambivalence. Journal of Personality and Social Psychology, 98, 450-468. https://doi.org/10.1037/a0017366

Miyamoto, Y., Ma, X., \& Wilken, B. (2017). Cultural variation in pro-positive versus balanced systems of emotions. Current Opinion in Behavioral Sciences, 15, 27-32. https://doi.org/10.1016/j.cobeha.2017. 05.014

Miyamoto, Y., \& Ryff, C. D. (2011). Cultural differences in the dialectical and non-dialectical emotional styles and their implications for health. Cognition \&amp; Emotion, 25, 22-39. https://doi.org/10. 1080/02699931003612114

Miyamoto, Y., Uchida, Y., \& Ellsworth, P. C. (2010). Culture and mixed emotions: co-occurrence of positive and negative emotions in Japan and the United States. Emotion, 10, 404-415. https://doi. org/10.1037/a0018430

Moeller, J., Ivcevic, Z., Brackett, M. A., \& White, A. E. (2018). Mixed emotions: network analyses of intra-individual co-occurrences within and across situations. Emotion, 18, 1106-1121. https://doi. org/10.1037/emo0000419

Newman, D. B., Sachs, M. E., Stone, A. A., \& Schwarz, N. (2020). Nostalgia and well-being in daily life: an ecological validity perspective. Journal of Personality and Social Psychology, 118, 325347. https://doi.org/10.1037/pspp0000236

Nezlek, J. B., \& Kuppens, P. (2008). Regulating positive and negative emotions in daily life. Journal of Personality, 76, 561-580. https://doi.org/10.1111/j.1467-6494.2008.00496.x

Oh, V. Y. S., \& Tong, E. M. W. (2021). Mixed emotions, but not positive or negative emotions, facilitate legitimate virus-prevention behaviors and eudaimonic outcomes in the emergence of the COVID19 crisis. Affective Science. https://doi.org/10.1007/s42761-021-00045-x

Orth, U., Clark, D. A., Donnellan, M. B., \& Robins, R. W. (2021). Testing prospective effects in longitudinal research: comparing seven competing cross-lagged models. Journal of Personality and Social Psychology, 120, 1013-1034. https://doi.org/10.1037/pspp0000358

Pallant, J. F., \& Lae, L. (2002). Sense of coherence, well-being, coping and personality factors: further evaluation of the sense of coherence scale. Personality and Individual Differences, 33, 39-48. https://doi.org/10.1016/S0191-8869(01)00134-9

Pinquart, M., \& Sorensen, S. (2001). Gender differences in self-concept and psychological well-being in old age: a meta-analysis. The Journals of Gerontology Series b: Psychological Sciences and Social Sciences, 56, P195-P213. https://doi.org/10.1093/geronb/56.4.P195

Putnick, D. L., \& Bornstein, M. H. (2016). Measurement invariance conventions and reporting: the state of the art and future directions for psychological research. Developmental Review, 41, 71-90. https://doi.org/10.1016/j.dr.2016.06.004

Rees, L., Rothman, N. B., Lehavy, R., \& Sanchez-Burks, J. (2013). The ambivalent mind can be a wise mind: emotional ambivalence increases judgment accuracy. Journal of Experimental Social Psychology, 49, 360-367. https://doi.org/10.1016/j.jesp.2012.12.017

Reich, J. W., Zautra, A. J., \& Davis, M. (2003). Dimensions of affect relationships: models and their integrative implications. Review of General Psychology, 7, 66-83. https://doi.org/10.1037/10892680.7.1.66

Rutkowski, L., \& Svetina, D. (2014). Assessing the hypothesis of measurement invariance in the context of large-scale international surveys. Educational and Psychological Measurement, 74, 31-57. https://doi.org/10.1177/0013164413498257 
Ryff, C. D. (1989). Happiness is everything, or is it? explorations on the meaning of psychological wellbeing. Journal of Personality and Social Psychology, 57, 1069-1081. https://doi.org/10.1037/00223514.57.6.1069

Ryff, C. D. (1995). Psychological well-being in adult life. Current Directions in Psychological Science, 4, 99-104. https://doi.org/10.1111/1467-8721.ep10772395

Savalei, V., \& Falk, C. F. (2014). Recovering substantive factor loadings in the presence of acquiescence bias: a comparison of three approaches. Multivariate Behavioral Research, 49, 407-424. https:// doi.org/10.1080/00273171.2014.931800

Schneider, I. K., \& Mattes, A. (2021). Mix is different from nix: Mouse tracking differentiates ambivalence from neutrality. Journal of Experimental Social Psychology, 95, 104106. https://doi.org/10. 1016/j.jesp.2021.104106

Sedikides, C., \& Wildschut, T. (2018). Finding meaning in nostalgia. Review of General Psychology, 22, 48-61. https://doi.org/10.1037/gpr0000109

Shrira, A., Palgi, Y., Wolf, J. J., Haber, Y., Goldray, O., Shacham-Shmueli, E., \& Ben-Ezra, M. (2011). The positivity ratio and functioning under stress. Stress and Health, 27, 265-271. https://doi.org/ 10.1002/smi.1349

Silvers, J. A., Hubbard, A. D., Biggs, E., Shu, J., Fertuck, E., Chaudhury, S., Grunebaum, M. F., Weber, J., Kober, H., Chesin, M., Brodsky, B. S., Koenigsberg, H., Ochsner, K. N., \& Stanley, B. (2016). Affective lability and difficulties with regulation are differentially associated with amygdala and prefrontal response in women with borderline personality disorder. Psychiatry Research: Neuroimaging, 254, 74-82. https://doi.org/10.1016/j.pscychresns.2016.06.009

Spencer-Rodgers, J., Peng, K., \& Wang, L. (2010). Dialecticism and the co-occurrence of positive and negative emotions across cultures. Journal of Cross-Cultural Psychology, 41, 109-115. https://doi.org/10. $1177 / 0022022109349508$

Springer, K. W., Hauser, R. M., \& Freese, J. (2006). Bad news indeed for Ryff's six-factor model of wellbeing. Social Science Research, 35, 1120-1131. https://doi.org/10.1016/j.ssresearch.2006.01.003

Taris, T. W. (2006). Is there a relationship between burnout and objective performance? a critical review of 16 studies. Work \&amp; Stress, 20, 316-334. https://doi.org/10.1080/02678370601065893

Thompson, M. M., Zanna, M. P., \& Griffin, D. W. (1995). Let's not be indifferent about (attitudinal) ambivalence. In R. E. Petty \& J. A. Krosnick (Eds.), Ohio State University series on attitudes and persuasion, Vol. 4. Attitude strength: Antecedents and consequences p. 361-386). Lawrence Erlbaum Associates, Inc.

Tong, E. M. W., Reddish, P., Oh, V. Y. S., Ng, W., Sasaki, E., Chin, E. D. A., \& Diener, E. (2021). Income robustly predicts self-regard emotions. Emotion. https://doi.org/10.1037/emo0000933

Vaccaro, A. G., Kaplan, J. T., \& Damasio, A. (2020). Bittersweet: the neuroscience of ambivalent affect. Perspectives on Psychological Science. https://doi.org/10.1177/1745691620927708

van Harreveld, F., van der Pligt, J., \& de Liver, Y. N. (2009). The agony of ambivalence and ways to resolve it: introducing the MAID model. Personality and Social Psychology Review, 13, 45-61. https://doi.org/ $10.1177 / 1088868308324518$

Wiese, C. W., Chen, Z. J., Tay, L., Friedman, E. M., \& Rector, J. L. (2019). The role of affect on physical health over time: a cross-lagged panel analysis over 20 years. Applied Psychology: Health and WellBeing, 11, 202-222. https://doi.org/10.1111/aphw.12149

Williams, P., \& Aaker, J. L. (2002). Can mixed emotions peacefully coexist? Journal of Consumer Research, 28, 636-649. https://doi.org/10.1086/338206

Wolf, E. J., Harrington, K. M., Clark, S. L., \& Miller, M. W. (2013). Sample size requirements for structural equation models: an evaluation of power, bias, and solution propriety. Educational and Psychological Measurement, 73, 913-934. https://doi.org/10.1177/0013164413495237

Publisher's Note Springer Nature remains neutral with regard to jurisdictional claims in published maps and institutional affiliations. 